\title{
Trading Favors - Examining the Temporal Dynamics of Reciprocity in Congressional Collaborations Using Relational Event Models
}

\author{
Laurence Brandenberger ${ }^{* \dagger 1,2}$ \\ ${ }^{1}$ Institute of Political Science, University of Bern, Switzerland \\ ${ }^{2}$ Department of Environmental Social Sciences, Swiss Federal Institute of Aquatic Science and \\ Technology (Eawag), ETH Domain, Switzerland
}

\begin{abstract}
Relational event models (REM) are a powerful tool for inference on dynamic network evolution. This paper examines the temporal dynamics of reciprocity in the setting of legislative cosponsorship in the 113th U.S. Congress (2013-2015). Rather than aggregating cosponsoring events into network snapshots, cosponsoring events are ordered in time and reflect an event sequence of members supporting bills at distinct points in time. Since legislative proposals are continuously drafted and introduced over the course of the 2-year cycle, the cosponsoring event sequence presents as time-dependent. Two alternative specifications of REMs are presented to accommodate such two-mode event sequences with time-varying composition changes in the target mode. The norm of reciprocity is tested to see if it affects a) new collaboration clusters emerging over time or b) the time-to-cosponsoring. Findings suggest that receiving cosponsoring support in the past, leads to future collaborations, however, this finding holds only for Republican members of Congress. Furthermore, reciprocity demands do not expedite cosponsorship support and members do not react faster to favors they received.
\end{abstract}

Keywords. relational event model, two-mode network, reciprocity, dyadic event sequence, endogeneity, Congress

*Corresponding author at: Institue of Political Science, University of Bern, Fabrikstrasse 8, CH-3012 Bern, Switzerland

E-mail address: laurence.brandenberger@ipw.unibe.ch

Orchid-ID: orcid.org/0000-0003-0392-9766

${ }^{\dagger}$ This work was supported by the Swiss National Science Foundation (Grant number 149410, 'Overlapping Subsystems: Identification and Integration of Fragmented Games in Swiss Water Politics'). The author would like to thank Philip Leifeld and Juergen Lerner for helpful comments and conversations. 


\section{Introduction}

Reciprocity is often referred to as one of the guiding norms for social interactions (Gouldner, 1960; Emerson, 1976). While many different theories of social exchanges and interactions state that reciprocity fosters under repeated actions (Gouldner, 1960; Melamed and Simpson, 2016) and builds trust and cohesion over time (Friedkin, 2004; Molm, Schaefer and Collett, 2007), few studies examine reciprocity at the micro-level as a dynamic mechanism in relational event sequences (e.g., Butts, 2008; Quintane et al., 2013; Kitts et al., 2016). How do nodes in a network react to network changes initiated by other nodes surrounding them that can be classified as reciprocated favors? This paper tackles this question by examining the dynamics of reciprocity in two-mode network event sequences of Congressional cosponsorship events using relational event models.

First introduced by Butts (2008), relational event models (REMs) can be used to model sequences of network events (or event streams). More and more studies are using event sequences to understand the evolution of network structures (Vu et al., 2011; Zenk and Stadtfeld, 2010; De Nooy and Kleinnijenhuis, 2013; Lerner, Bussmann, Snijders and Brandes, 2013; DuBois, Butts and Smyth, 2013; Quintane et al., 2013; Liang, 2014; Patison et al., 2015; Tranmer et al., 2015; Welbers and de Nooy, 2014; Kitts et al., 2016; Leenders, Contractor and DeChurch, 2016; Pilny et al., 2016; Xia, Mankad and Michailidis, 2016; Quintane and Carnabuci, 2016; Pilny et al., 2017). However, few studies examine two-mode network event sequences (De Nooy, 2011; Stadtfeld and Geyer-Schulz, 2011; Quintane et al., 2014; Malang, Brandenberger and Leifeld, 2017).

The added temporal information on tie formation can be used to increase certainty in dominant network structures and strengthen the testing of causal links in network formation and evolution mechanisms. By examining individual cosponsoring actions, this article aims at examining whether reciprocity plays an convincing role in cosponsorship networks and whether members of Congress react to supportive gestures by reciprocating them in the near future. 
Congressional cosponsorship is an inherently social act where new legislations are darfted and proposed and cosponsoring signatures are used as signals to fellow members of Congress as well as to said member's constituents on positions or interests of each member (Fowler, 2006; Mayhew, 1974; Campbell, 1982). Two types of cosponsoring activities are examined in this article. The first deals with what Fowler (2006) calls 'active cosponsorship' which refers to the support that is given to a soon to be introduced bill, for instance by drafting it, recruiting sponsors or otherwise promoting the bill. Active cosponsoring events present as cluster of members working on the same bill and introducing it to Congress at a distinct point in time. The formation of these cosponsoring clusters can then be viewed as a sequence of clusters emerging over time. The second type of cosponsoring activity deals with 'passive cosponsorship' (Fowler, 2006). Passive cosponsoring refers to the support individual members of Congress voice for a bill after it has been introduced. As such, passive cosponsoring events present as two-mode events involving a member and a bill and the specific date the cosponsorship signature was given. This sequence of events involves temporally spread out activities after the introduction of each bill.

Both types of event sequences show an inherent time-dependence in their node set composition. In other words, target nodes (bills) are continuously drafted and introduced over the entire event sequence and this composition change affects both estimation strategies for REMs as well as the construction of the dynamic operationalization of reciprocity. The importance of this time-varying node set composition becomes apparent, when comparing two possible event sequences. Figure 1 shows a snapshot of a two-mode network, originating from two different event sequences. The difference in the timing and sequence of events becomes evident when examining a four-cycle. A four-cycle involving nodes $i_{1}, i_{2}, j_{1}$ and $j_{2}$-shaded ties in Figure $1-$ is closed within the first four events in sequence A (and is reinforced afterwards) and takes much longer to close in sequence B (event 16). By taking the timing and the sequence of network ties into account, the four-cycle in sequence B appears much weaker. Long time intervals between the four ties, or an abundance of different network ties forming in-between these events serve as an indicator that four-cycles in sequence B are not a distinct mechanism of tie formation. 


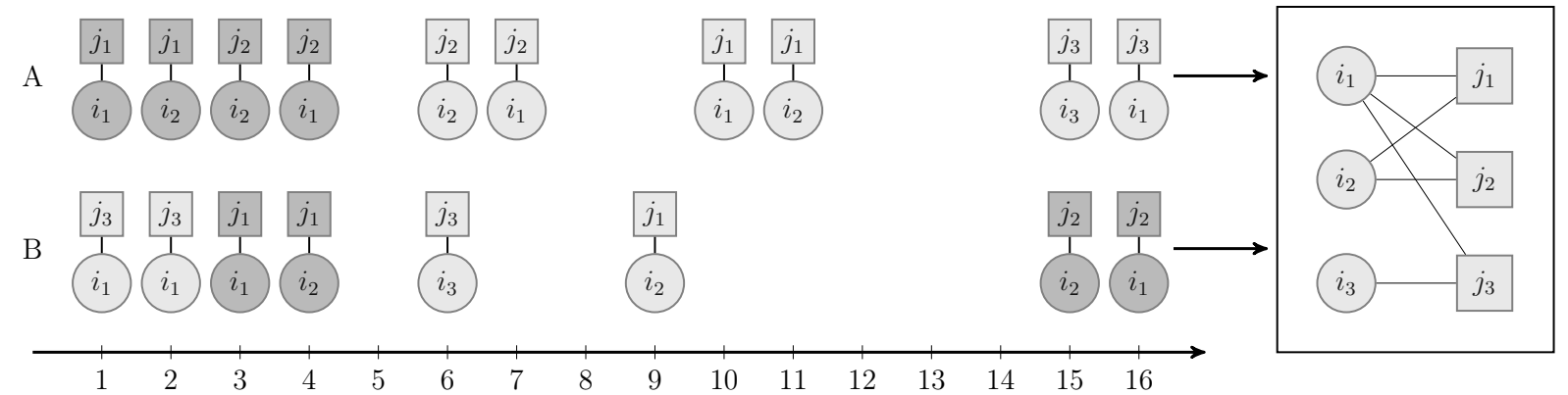

Figure 1: Two possible event sequences resulting in the same network snapshot. Sender nodes are represented as circles, target nodes as squares. Examining the sequence of network events allows for stricter test of network formation mechanisms. However, if target nodes are introduced over time, network formation mechanisms have to be adjusted. The four-cycle involving the shaded ties closes faster in sequence A. However, if target node $j_{2}$ is introduced to the sequence only at event time 15 , the four-cycle in sequence B closes equally fast.

However, this finding only holds, if all nodes in the target mode are available throughout the entire event sequence. If, for instance, node $j_{2}$ in sequence B only becomes available at event time 15 , the conclusion about four-cycles being weakly related to the structural evolution in sequence B may be wrong. If $j_{2}$ is only available at event time 15 , the four-cycle closes at its earliest possibility. Therefore, the temporal dependence in the node set composition of one or both of the modes is crucial for the analysis of the evolution of two-mode networks.

This paper expands on the statistical methodology of relational event models and proposes two methods of analysis for two-mode networks with time-varying node set composition in the target mode. A large share of two-mode networks shows an inherent time-dependence in their target mode. For instance, the target mode of author-paper networks is a sequence of papers, where ties to each paper are fixed in time and cannot be drawn later on. Other examples of two-mode networks with a time-dependent target mode include networks of event attendance, or networks of research projects and associated departments, where ties indicate prolonged but temporally limited engagements.

This paper proposes two different estimation strategies to handle REMs with time-varying node set composition in the target mode. The first adaption of REMs examines how clusters of 
members of Congress emerge over time and affect the subsequent formation of new collaboration clusters. Apart from congressional collaboration clusters, other two-mode event sequences that exhibit unrepeatable target nodes over time can be examined in the same manner, such as dynamic co-authorship event sequences, research cluster sequences or event attendance networks.

The second adaption explores the reaction time of members embedded in networks by examining the time it takes until a tie is formed. Using passive cosponsorship data, the method is used to examine whether the norm to reciprocate previous support expedites a member's decision to support a newly introduced bill. By examining the time it takes for a member to cosponsor a bill, the model can test whether receiving a favor from one of the original cosponsors is reciprocated by issuing cosponsoring support at the next possible event. Other applications of this REM variation could examine the time it takes an actor to veto a specific proposal or examine which intermediate actions by others in the network spur an actor to issue a sanction (i.e., by examining time-to-sanction in a duration model).

Results of these two REM variations on cosponsorship suggest that in both active and passive cosponsoring, reciprocity may play a different role than previously assumed. Previous studies on cosponsorship report strong tendencies of members to reciprocate cosponsorship support (Bratton and Rouse, 2011; Cranmer and Desmarais, 2011). However, when analyzing cosponsorship as an event sequence, results show a slightly more diverse picture. In active cosponsorship, Republican members show strong tendencies to reciprocate support that was issued in the near past, whereas Democratic members of Congress show negative effects of reciprocity on future collaborations. In passive cosponsorship, reciprocity does not expedite support statements, in fact, for Democratic members, the effects are reversed and support for bills that can be seen as a show of reciprocity are issued later in time and not directly after favors were given.

These findings suggest that REM specifications for these two-mode event sequences are able to examine common network patterns - such as reciprocity - whilst adhering to the com- 
plex dynamics of composition changes in the target mode and deliver temporally sensitive findings that outshine cross-sectional findings.

After a section on the role of reciprocity in legislative networks, two estimation strategies for REMs are discussed, followed by a discussion of the effect of time-varying node set compositions on the calculation of the endogenous reciprocity statistic. All suggested procedures in this contribution are made available in the BLINDED-package (BLINDED) for the statistical computing environment R (R Core Team, 2016).

\section{Trading Favors - Congressional Cosponsoring and the Norm of Reciprocity}

Cosponsorship of legislative proposals (henceforth referred to as bills ${ }^{1}$ ) has been widely studied with and without a network approach (examples include Mayhew, 1974; Kessler and Krehbiel, 1996; Wilson and Young, 1997; Fowler, 2006; Barnello and Bratton, 2007; Cranmer and Desmarais, 2011; Desmarais and Cranmer, 2012; Kirkland, 2011; Kirkland and Gross, 2014; Lee, Magallanes and Porter, 2015; Craig et al., 2015). There are several intrinsic reasons for a member of Congress to cosponsor a bill. First, the content of the bill reflects a member's own viewpoints on the subject, motivating them to support the proposition. The importance of signaling a position to a member's constituents or other members of Congress could be one of the motivating personal factors (Mayhew, 1974; Campbell, 1982; Kessler and Krehbiel, 1996). Second, cosponsors may be influenced by sponsors or original cosponsors, with whom they worked together on the bill or lobbied in Congress for support. Third, it is possible that the action of other members convince a member to support a specific bill (e.g., Tam Cho and Fowler, 2010; Craig et al., 2015). Fourth, members of Congress can be brought together by lobbying groups outside parliament to carry a bill (see for instance Hojnacki and Kimball, 1999). Furthermore, empirical findings further suggest that triadic closure and homophily effects are powerful structural patterns in cosponsorship networks (Bratton and Rouse, 2011; Cranmer and Desmarais,

\footnotetext{
${ }^{1}$ The term bill is used for any piece of legislation, be it a bill, a resolution or an amendment.
} 
2011). Homophily effects span across the dimensions of gender, party, same state and ethnicity (Cranmer and Desmarais, 2011; Craig et al., 2015). Lastly, the social norm to reciprocate previous support may foster lively cosponsoring activities among members of Congress. Issuing cosponsoring support for a bill may guarantee future support from other members as the issued support can act as a gift sharing action that demands reciprocation through social convention.

This article focuses on this exchange mechanism-reciprocity-as an intrinsic reason to collaborate on and cosponsor new bills. Reciprocity, also referred to as dyadic exchange, favor trading or mutuality, refers to the dyadic construct that shapes the interaction patterns of two actors (Wasserman and Faust, 1994). It measures to what extent an interaction or exchange takes place between two actors $i$ and $j$ embedded in network $N$ :

$$
\operatorname{reciprocity}(N)=\sum_{i, j} N_{i j} \cdot N_{j i}
$$

Social Exchange Theory postulates that reciprocity is an important building block of social interactions (for an overview, see Emerson, 1976; Cook et al., 2013). Actors choose to 'invest' in certain social bonds and in turn expect rewards from their investment. If these rewards are not satisfactory, actors will modify their behavior or choose to discontinue a relationship (Emerson, 1976; Ikkink and Van Tilburg, 1999, 341). Thus reciprocity emerges as a strong mechanism that guides social interactions over time.

Furthermore, reciprocity is considered one of the most important norms and is crucial in the maintenance of stable social systems (Gouldner, 1960). In game theoretic settings, it has been shown that reciprocity is a basic element of human behavior that strengthens trust bonds between different actors (e.g., Axelrod, 2006; Trivers, 1971; Berg, Dickhaut and McCabe, 1995; Dufwenberg and Kirchsteiger, 2004; Falk and Fischbacher, 2006). In network settings, reciprocity is a central component in explaining the structure of friendship networks (for example Mercken et al., 2010; Schaefer et al., 2010; Harrigan and Yap, 2017), animal social networks (e.g., Tranmer et al., 2015), trade and social commerce networks (e.g., Stephen and Toubia, 2009), interpersonal relationships and exchanges (e.g., Plickert, Cote and Wellman, 2007), on- 
line social networks (e.g., Ammann, 2011; Surma, 2016) or inter-state networks (e.g., Cranmer, Heinrich and Desmarais, 2014; Maoz et al., 2006), to name a few. Empirical findings on cosponsorship show that by lending cosponsoring support to particular members involved in drafting a bill, the focal member may be inclined to reciprocate previous support (Bratton and Rouse, 2011; Cranmer and Desmarais, 2011).

A central component of reciprocity is time. Emerson $(1976,359)$ stresses the importance of studying long time-spans of social relations, since the inherent pattern exhibited through reciprocal behavior only emerges in longitudinal settings. In long-term settings repeated interactions between actors often exhibit a great amount of reciprocity or redundancy. Several previous studies observe these temporal dynamics of reciprocity in various settings.

A first study by Kitts et al. (2016) investigates the time horizon of reciprocity dynamics by studying patient exchange event sequences. By classifying two forms of patient exchanges, complementary exchanges (where patients are exchanged across-specialties) and competitive exchanges (transfers within specialties), they are able to show that reciprocity effects differ according to the setting. In complementary exchanges they find ample evidence of reciprocity effects, both with hospitals that have transferred many of their patients to them in the past (short-term and long-term) and with hospitals from whom they received the most patients in the past (short-term) (Kitts et al., 2016, 38-9). In competitive exchanges no reciprocity effects are present, indicating that an alternative logic guides these exchanges (Kitts et al., 2016, 40).

Another study by Leifeld and Brandenberger (2017) finds that reciprocity is the driving force in coalition formation processes in policy debates. Using data from policy actors' statements on how to address the pension problem in Germany over the course of a nine year long debate, they are able to show that actors reciprocate supportive statements on policy beliefs from people with whom they agreed upon policy beliefs in the recent past. Furthermore, actors have a tendency to pick up policy beliefs from actors with whom they disagreed upon in the past and proclaim their disagreement with these beliefs anew. These positive and negative forms of reciprocity can account for bonding strategies seen in policy networks. 
A third study by Quintane et al. (2013) shows evidence of short-term reciprocity effects by examining e-mail exchanges among members of two project teams. They use short-term and long-term statistics to evaluate the effects of reciprocity on the hazard of event occurrence. Short-term reciprocity is captured by past interactions involving two members in the past 24 hours, where as long-term reciprocity is operationalized as the frequency of reciprocated actions during the past trimester (Quintane et al., 2013, 533-4). They find that both short-term and long-term reciprocity are positive predictors of e-mail communications, with the shortterm effect exhibiting slightly stronger effects (Quintane et al., 2013, 535-6). They conclude that "while the very notion of reciprocity invokes the expectation of a response or reply, the observation of reciprocity during different time frames [i.e., short-term and long-term] may be a reflection of deep sociotemporal cycles that guide and reflect norms of behavior" (Quintane et al., 2013, 536).

These studies show the importance of accounting for time between reciprocated dyadic events. The present study aims at studying reciprocity dynamics in legislative collaboration events and asks the question to what extent are cosponsoring activities among members of Congress guided by reciprocity, and more importantly, what time horizons matter in explaining reciprocity effects? Previous studies have shown that congressional cosponsorship is, among other factors, guided by reciprocity (Bratton and Rouse, 2011; Cranmer and Desmarais, 2011). This paper examines whether cosponsoring signatures are issued in response to temporally close exchanges of support, or if reciprocity becomes evident only in the long run as a result of aggregated events.

To answer these questions, legislative cosponsoring signatures are analyzed as a sequence of events. Legislative reciprocity has been studied widely using aggregated network snapshots, either as cross-sectional snapshots (Bratton and Rouse, 2011; Cranmer and Desmarais, 2011) or in a longitudinal setting using multiple snapshots where ties are aggregated over different time slices (Desmarais and Cranmer, 2012). This paper uses a different approach.

Rather than aggregating cosponsoring events into network snapshots, the events are analyzed individually as micro-steps in an event sequence. As such, each event consists of a 
member of Congress that ties to a legislative proposal at a distinct point in time, forming a two-mode network event sequence. Two-mode networks are a special kind of network where sender mode and target mode stem from different sets of nodes that can only interact between the modes, not within (Borgatti and Everett, 1997). Examples of two-mode networks are numerous and include author-paper networks (e.g., Newman, Strogatz and Watts, 2001; Morris, Yen et al., 2005), company-board member networks (e.g., Robins and Alexander, 2004; Everard and Henry, 2002), research projects-research departments networks (e.g., Mote, 2005), sexual affiliation networks (e.g., Niekamp et al., 2013; Ergün, 2002), online group activity networks (e.g., Zhu, Huang and Contractor, 2013; Conaldi and Lomi, 2013) and event attendance networks (e.g., Faust et al., 2002). Several network studies use projection methods to transform two-mode networks into one-mode networks for the sake of simplification (Borgatti and Everett, 1997; Latapy, Magnien and Del Vecchio, 2008; Guillaume and Latapy, 2006). Two-mode event sequences are difficult to project since the two events that result in a one-mode tie could have occurred at two different time points and it is unclear which time point should be allocated to the one-mode event. Broccatelli, Everett and Koskinen (2016), however, provide an innovative method to transform two-mode event sequences into bi-dynamic line-graphs. This article focuses on two-mode sequences as they are and refrains from projecting to avoid additional potential problems with projection, such as loss of information on the target mode or an overestimation of triadic closure effects (Borgatti and Everett, 1997; Latapy, Magnien and Del Vecchio, 2008; Opsahl, 2013; Everett and Borgatti, 2013).

Figure 2 represents an extract from a possible cosponsoring event sequence. Two different types of events can be identified. The first event type deals with active cosponsoring. Active cosponsoring represents members who pose as 'original cosponsors' on soon to be introduced bills. A cluster of original cosponsors often drafts and promotes the bill before one of them, the sponsor, presents it to Congress (Fowler, 2006, 458-9). Since the rules of the U.S. House of Representatives do not allow more than one official sponsor for each bill, additional members who were involved in drafting or promoting a bill are listed as 'original cosponsors' upon the introduction of the bill to Congress. 


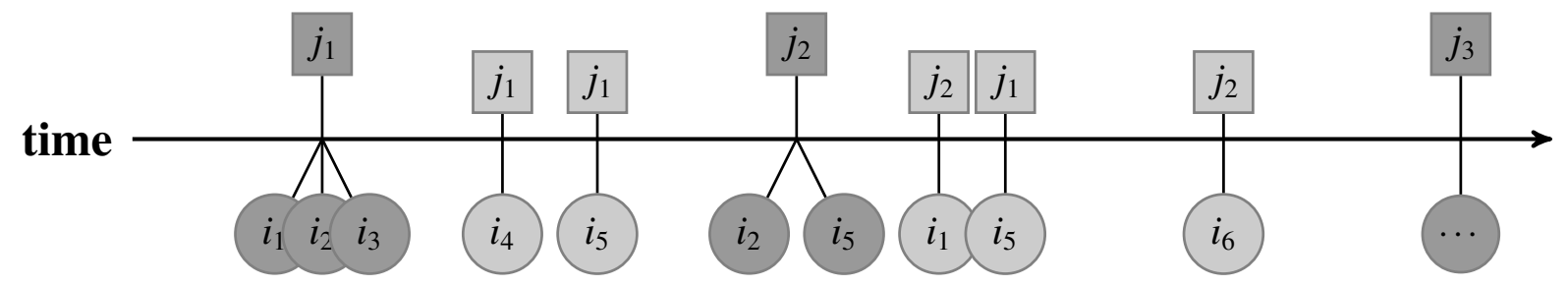

Figure 2: Illustration of a cosponsoring event sequence. Members are represented as circles, bills as squares. Dark-grey shaded events are active cosponsoring events, where members introduce new bills to Congress. Lightly-shaded bills are passive cosponsoring events, where members issue support for already introduced bills.

The question is, how does reciprocity shape new collaboration clusters? In a first analysis, this paper examines whether the norm of reciprocity brings members to work together if they have previously received cosponsoring support from one another.

The second event type deals with passive cosponsoring. Passive cosponsoring refers to Congressional support issued after a bill has been formally introduced to Congress. Here, members choose to sign a bill to signal their position, reciprocate previous support from the sponsor and original cosponsors in the past or try to make new alliances (Fowler, 2006, 4589). However, how exactly does the norm of reciprocity express itself with regard to the timing of these cosponsoring events? In a second analysis, this paper examines whether the norm of reciprocity brings members to show their support for a newly introduced bill earlier, if they have previously received support for their own bills by members that introduced the new bill. In other words, it is examined if previous support triggers actions that can be classified as expressions of reciprocity. The details of how the two event types are analyzed are described in the following section. 


\section{Methodological Approach: Expanding Two-Mode Relational Event Models}

\section{Relational Event Models: a Brief Overview}

Relational event models build on survival or event history analysis. A sequence of events involving a sender node, a target node and a time stamp (or ordinal time) represent microsteps (or individual edges occurring over time) in a network. The underlying assumption of REMs is that past network events and exogenous covariates affect the occurrence of events. Controlling for said endogenous and exogenous covariates, these events can be considered conditionally independent of one another and can therefore be analyzed using conventional regression models (Butts, 2008; Lerner, Indlekofer, Nick and Brandes, 2013). REMs model this occurrence of events using a piecewise constant hazard model, where the hazard of an event occurring is held constant within a time interval.

The likelihood that a specific number of events $n_{i j}(t)$ take place on a dyad $(i, j)$ within the time interval $t$ is given by the hazard rate $\lambda_{i j}(t)$, and then multiplied by the survival function $\exp \left(-\lambda_{i j}(t)\right)$, which captures all events that could have occurred at time $t$ yet did not (see Lerner, Bussmann, Snijders and Brandes 2013, 18-9 and Butts 2008, 161-3):

$$
\operatorname{Pr}\left(n_{i j}(t)\right)=\frac{\lambda_{i j}(t)^{n_{i j}(t)} \cdot \exp \left(-\lambda_{i j}(t)\right)}{n_{i j}(t) !} .
$$

Furthermore, multiplying over all dyads and all time intervals $t_{1}$ to $t_{N}$ in the event sequence $E$, the probability density of the event sequence is

$$
f_{\lambda}\left(E ; \theta^{\lambda}\right)=\prod_{t=t_{1}}^{t_{N}}\left(\prod_{i j \in D_{a c t}(t)} \frac{\lambda_{i j}(t)^{n_{i j}(t)}}{n_{i j}(t) !}\right) \cdot \exp \left(-\sum_{i j \in D} \lambda_{i j}(t)\right),
$$

where $D_{a c t}(t)$ represents all dyads in which at least one event occurred over the entire event sequence and $D$ represents all possible events that could have potentially occurred (Lerner, Bussmann, Snijders and Brandes, 2013, 18-9). For a more detailed derivation and specification 
of the rate function, see Lerner, Bussmann, Snijders and Brandes (2013, 14-9) or Butts (2008, 161-3). $D$ represents the risk set, which can be specified dynamically for each time interval $t$.

To estimate the effects endogenous or exogenous variables have on the hazard rate, REMs use duration models to model time-to-next-event for continuous-time event sequences and conditional logistic regression models for ordinal-time sequences to model the effects on the probability that an event occurred now, given it has not occurred yet (Butts, 2008).

\section{Analyzing Sequences With Unique Target Nodes}

Active cosponsoring events group together over time, representing clusters of sender nodes (i.e., members) involved in unique target nodes (i.e., bills) that do not repeat themselves over the course of the event sequence. To analyze the formation of new sponsoring clusters, each introduction of a new bill represents an unrepeatable event in the event sequence. The target mode, therefore, consists of bills that are continuously drafted by one or more members of Congress that represent the sender mode.

This specific form of the event sequence, involving unrepeatable target nodes, calls for an adaption of the ordinal-time relational event models presented by Butts (2008). The reason is that the corresponding events are only at risk at one time during the sequence and no null-events can be created for the true events. As such, the event history framework that is generally used to model ordinal event sequences via conditional logistic regressions, poses a problem.

Figure 3 illustrates an event sequence where the target nodes represent parliamentary bills. These bills can only be introduced once over the entire event sequence and can therefore be considered non-repetitive. One or more sender nodes (i.e., members) work together to introduce the bill at time $t$. Since bills $j$ are non-repeatable, they cannot be used in the creation of the risk set $D$ in Equation 3. However, instead of modeling the hazard of event occurrence, a logistic regression can test which factors have lead specific members to engage in the creation of a bill while others have not. ${ }^{2}$ For each unrepeatable or unique bill in the target mode new events are

\footnotetext{
${ }^{2}$ This approach is similar to the use of logistic regressions in Exponential Random Graph Models, but, as cluster formations are modeled as micro-steps over time, the estimation of the parameters affecting cluster formation do not violate the independence assumption (Butts, 2008; Lerner, Indlekofer, Nick and Brandes, 2013).
} 


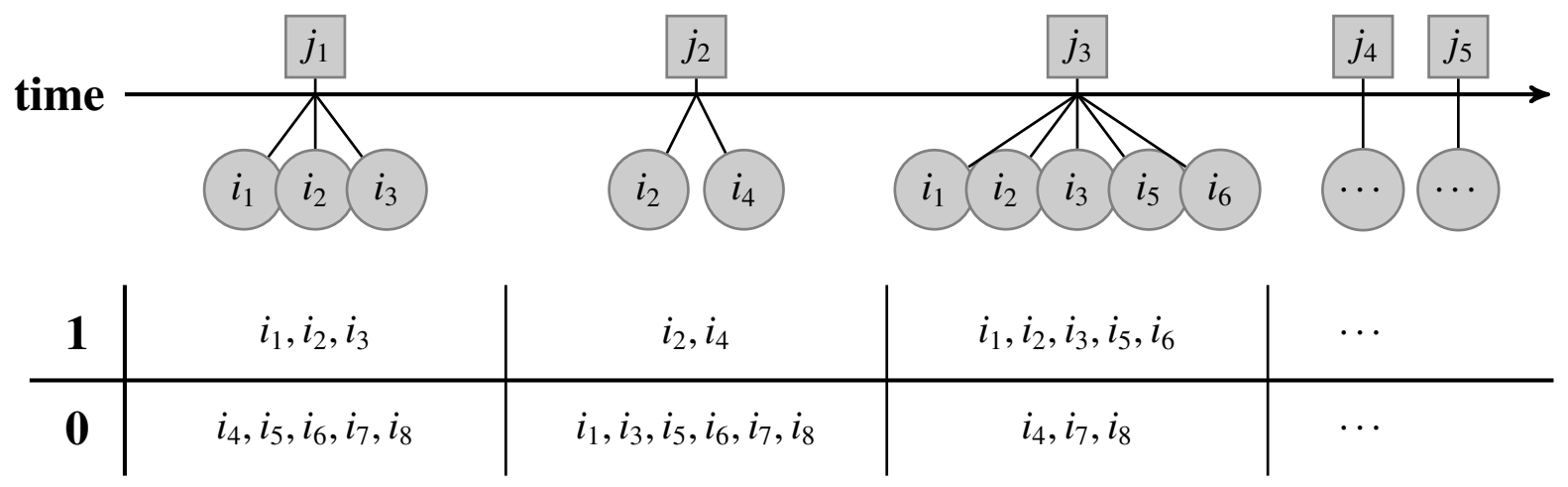

Figure 3: Event sequence where cluster of nodes simultaneously join the network. Sender nodes are represented as circles, target nodes as squares. A logistic regression can be used to examine which factors lead to the emergence of a specific collaboration cluster by adding null-events for sender nodes that did not engage in the respective target node.

created with members of Congress that did not engage in the bill, and therefore form a control group.

In the example sequence in Figure 3, the second bill was sponsored by two members $\left(i_{2}\right.$, $\left.j_{2}\right)$ and $\left(i_{4}, j_{2}\right)$. As such, all other unique members form a control group and are added as null events in the form of edges $\left(i_{x}, j_{2}\right)$, with $x$ referring to members other than $i_{2}$ or $i_{4}$. Combining true events and control events for each bill results in a dataset consisting of groups of 0/1cases. Temporal reciprocity statistics as well as other endogenous variables can be calculated for each true and control event. A logistic regression over all bill-clusters determines which endogenous and exogenous factors are predictive of members engaging with other members in the introduction of a new bill. This model allows the examination of whether members start working together in order to reciprocate cosponsoring support on previous bills.

\section{Analyzing Sequences With Time-Varying Node Set Compositions}

Passive cosponsoring event sequences preset as another interesting event sequence. As bills are continuously drafted and introduced to Congress, the target nodes in the event sequence present as time-dependent, making the existence of an event (i.e., a member cosponsoring a 
bill) dependent upon its introduction status. Each introduction of a new bill to Congress spurs new passive cosponsoring events as a reaction to said introduction.

Rather than examining time-to-next-event or the ordinal sequence of events, as done in other REM approaches, the introduction events can be used to examine time-to-cosponsoring, i.e., the reaction time until a member of congress signals support to an introduced bill by adding their signature to it. New Congressional bills are continually drafted, however, once created, bills can only be supported until they have passed (or failed) a vote. Therefore, after a bill has been voted on, no new supporting ties can link to it. Thus, each introduction of a new bill rewinds the clock for all subsequent events on that bill. The time until a sender node engages in a newly created target node may therefore be used as a rate indicator, or duration. Duration in the time-to-cosponsoring model is calculated as

$$
\operatorname{duration}\left(G_{t}, a, b\right)=t^{p c}(a, b)-t_{e}^{a c}(i, b),
$$

the current time $t$ minus the time $t_{e}$ in the network of past events $G_{t}$, when bill $b$ was first introduced to Congress by active cosponsoring members $i$ (see Figure 4).

The faster the cosponsoring support is issued after the formal introduction of the bill, the stronger the signal of the member's position on the issue or their willingness to form future partnerships. Therefore, passive cosponsorship can be modeled using the time-since introduction of the bill as duration in a stratified Cox model.

This model allows the question whether members of Congress tend to issue support statements faster in order to reciprocate previous support by one of the active sponsors of the bill. More specifically, the model can test whether members react to favors by reciprocating soon after receiving them. 


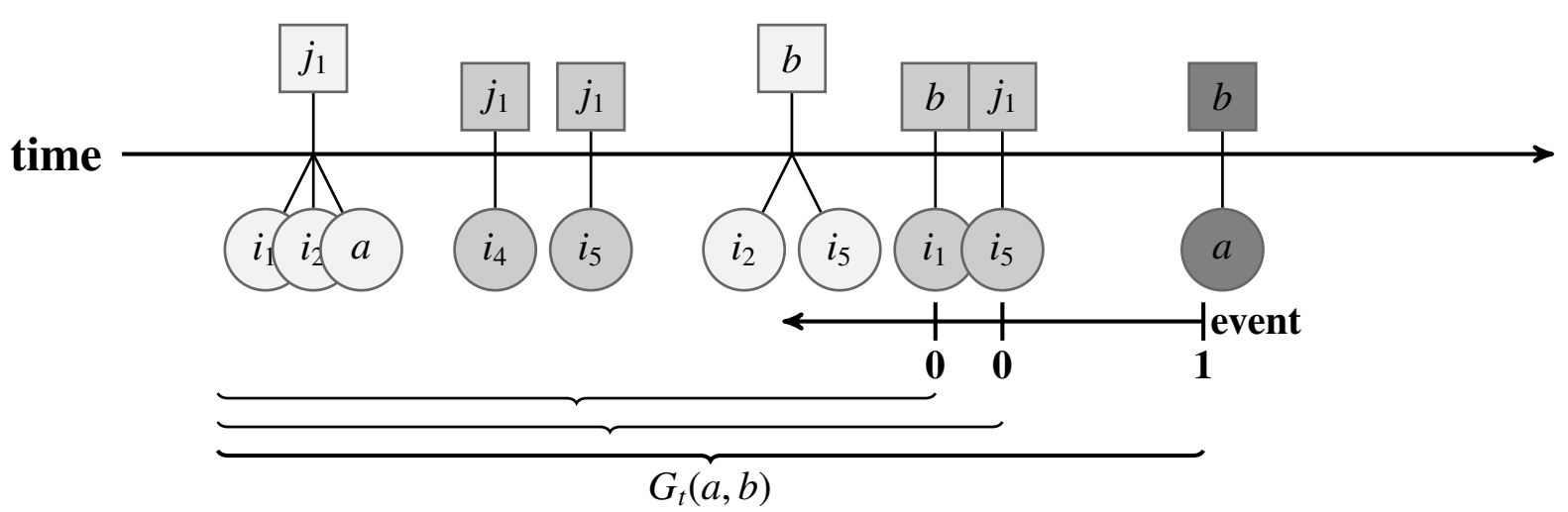

Figure 4: Passive cosponsorship event sequence. Sender nodes are represented as circles, target nodes as squares. A stratified Cox model can be used to examine time-to-cosponsoring. For instance, event ( $a, b)$ could have occurred on two previous events since the target bill was introduced. As such, the event creates two null-events that form the control group for previous events.

\section{Endogenous Reciprocity Statistics}

Reciprocity as a dynamic, closing four-cycle. In the two-mode cosponsorship network (M), reciprocity is captured via a four-cycle statistic.

$$
\operatorname{reciprocity}(M)=\sum_{i \neq k, j \neq l} M_{i j} \cdot M_{k j} \cdot M_{i l} \cdot M_{k l}
$$

The statistic captures a sender $i$ 's tendency to engage in a target node $j$ that is linked to by other senders $k$ with whom $i$ engaged in other targets $l$. In the dynamic setting of two-mode relational event models, reciprocity is operationalized as a so-called closing four-cycle, where three events in the past build up a four-cycle and the current in the sequence closes it. The events that occurred prior to a focal event in the event sequence form a network of past events:

$$
G_{t}=G_{t}(E)=\left(A ; B ; w_{t}\right)
$$

where $E=\left(e_{1}, e_{2}, \ldots, e_{n}\right)$ represents the set of events, $A$ is the set of nodes from the first mode, $B$ the set of nodes from the second mode and $w_{t}$ is the weight function that is applied to each event before time $t$. 
The weight function can take different forms, with its simplest form representing a $0 / 1$ weight for past events:

$$
e_{t}(i, j)= \begin{cases}0 & \text { if } w_{e}=0 \\ 1 & \text { if } w_{e}>0\end{cases}
$$

Alternatively, the weight function $w_{t}$ can use an exponential decay, so that events which occurred in the recent past are weighted more than events that took place further in the past.

$$
w_{t}(i, j)=\sum_{\substack{e: a_{e}=i, b_{e}=j, t_{e}<=t}}\left|w_{e}\right| \cdot e^{-\left(t-t_{e}\right) \cdot\left(\frac{\ln (2)}{T_{1 / 2}}\right)} \cdot \frac{\ln (2)}{T_{1 / 2}}
$$

where $i=a_{e} \in A$ and $j=b_{e} \in B, w_{e}$ is the weight of the prior event $e, t$ is the current time, $t_{e}$ is the time of the prior event $e . T_{1 / 2}$ represents the value of the half-life parameter. The half-life parameter specifies at which rate the weight of past events diminishes. A larger halflife parameter results in a slower decay, which means that time differences matter less when looking back over the past events (Lerner, Bussmann, Snijders and Brandes, 2013).

To examine whether reciprocity plays a role in legislative cosponsoring, reciprocity is operationalized as a closing four-cycle, where the endogenous network statistic is given more weight to the present event if it closes an open four-cycle:

$$
\text { closingFourCycle }\left(G_{t} ; a, b\right)=\frac{\sum_{\substack{i \in A \\ j \in B}} e_{t}(a, j) \cdot e_{t}(i, b) \cdot e_{t}(i, j)}{\sum_{\substack{i \in A, j \in B}} e_{t}(i, b) \cdot e_{t}(i, j)}
$$

The effect measures whether $a$ has a higher tendency to tie to $b$ if $a$ shared many other targets $j$ with other senders $i$ in the past, and said senders $i$ tied to $b$. The statistic is scaled using the sum of all events involving dyads $\{i, b\}$ and dyads $\{i, j\}$ because with the passage of time, the frequency counts increase and would otherwise distort the four-cycle statistic (Butts, 2008; Quintane et al., 2014). 
Alternatively, the statistic can be adapted to include exponential time-weighting:

$$
\operatorname{closingFourCycle}\left(G_{t} ; a, b\right)=\sum_{\substack{i \in A, j \in B}} w_{t}(a, j) \cdot w_{t}(i, b) \cdot w_{t}(i, j)
$$

Each of the past three events is weighted according to time. The longer ago and the fewer times a tie was drawn in the past, the less weight is given to the current event for the respective statistic. As such, the four-cycle effect is stronger if the four events occurred in close temporal proximity to each other. No additional scaling is necessary for this statistic, as the weighted past events already account for the passage of time.

Reciprocity in active cosponsoring. For active cosponsorship, reciprocity is measured by the number of times the current member $a$ has received cosponsoring support from another member $i$ and subsequently starts working with $i$ on a new bill $b$. Due to the time-varying nature of the two-mode event sequence of active and passive cosponsorship, the weighted fourcycle statistic in Equation 10 is adapted.

Since the present event $(a, b)$ takes place at the same time as event (i, b) for the active cosponsoring sequence, there is no need to weight this event, which is why the event is reduced to a simple 0/1-dummy using edge-function $e_{t}^{a c}$ in Equation 11. The superscripts ${ }^{a c}$ and ${ }^{p c}$ to the edge- and weight-functions in Equations 11-13 represent active and passive cosponsoring events, respectively.

The time-weighting of dyad $(i, j)$ presents an additional problem because more weight is given to cosponsoring events of $i$ that occurred in close proximity to the present event. Figure 5 exemplifies the problem. Three sequences are presented, named $A, B$ and $C$ and show closing four-cycles for event (a,b) at time $t=60$. Sequence $A$ and $B$ differ only by event (i, j) which occurs faster in sequence $A$ and later in sequence $B$. Intuitively, the four-cycle in sequence $A$ should be given more weight, since $i$ decided to cosponsor $j$ faster than in sequence $B$, indicating stronger support for this bill. However, the weight-function $w_{t}$ gives more weight 


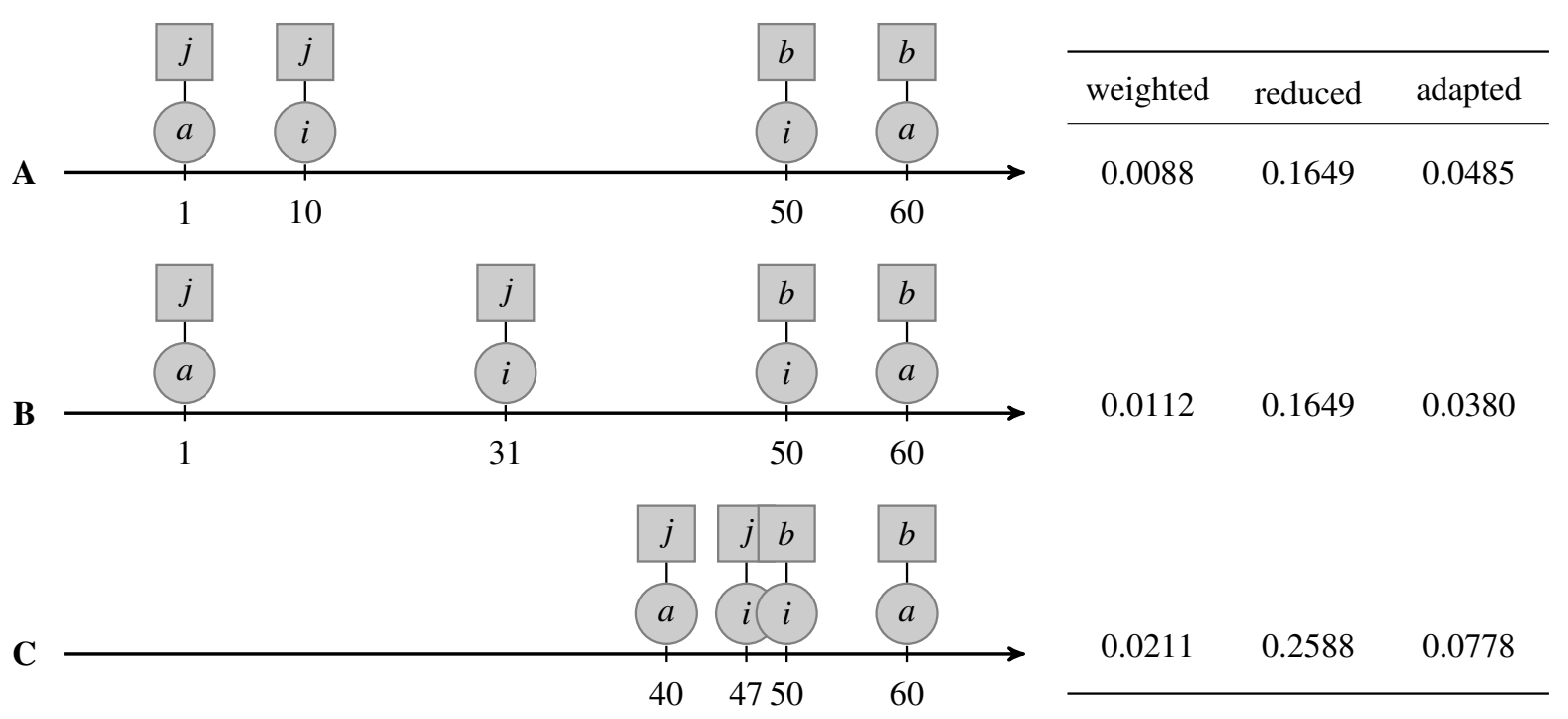

Figure 5: Effects of fully time-weighted four-cycle statistics, reduced time-weighted statistics and adapted time-weighted statistics are presented using three example event sequences. A fully time-weighted statistic results in a larger four-cycle statistic for event sequence B than $\mathrm{A}$, even tough it took $i$ longer to react to the introduction of bill $j$ in sequence $\mathrm{B}$ than $\mathrm{A}$. To correct this, the reduced time-weighted statistic does not weight the appearance of event $(i, j)$ in time, resulting in the same four-cycle statistic for both sequences A and B. Alternatively, the adapted four-cycle statistic can account for the time it took $i$ to cosponsor $j$, resulting in a higher four-cycle statistic for sequence A than B.

to event closer to the current event, lending more weight to the four-cycle in sequence $B$ (see tabled values for 'weighted' in Figure 5). To correct this, the past event involving ( $i, j)$ can be reduced to a 0/1-weight (labeled 'reduced' in Figure 5). Alternatively, the reaction time of $i$ to bill $j$ can be incorporated into the four-cycle statistic by adding an additional exponential weight involving said reaction time, as done in Equation 12 (labeled 'adapted' in Figure 5). Sequence $\mathrm{C}$ demonstrates that events closer in time to the current event are given more weight in all three calculations of the statistics.

Lastly, in order to calculate the average closing four-cycle effect for each current active sponsor of bill $b$, Equation 12 has to be divided by the number of active cosponsors of bill $b$ (see Equation 13). 


$$
\begin{aligned}
\text { reciprocity_activeCosp }\left(G_{t} ; a, b\right) & =\sum_{i \in A \backslash\{a\} ; j \in B \backslash\{b\}} w_{t}^{a c}(a, j) \cdot e_{t}^{a c}(i, b) \cdot e_{t}^{p c}(i, j) \\
& =\sum_{i \in A \backslash\{a\} ; j \in B \backslash\{b\}} w_{t}^{a c}(a, j) \cdot e_{t}^{a c}(i, b) \cdot e_{t}^{p c}(i, j) \cdot e^{\left(-\left(\left|t_{a j}-t_{i j}\right|\right) \cdot \frac{\ln (2)}{T_{1 / 2}}\right)} \\
& \stackrel{\sum_{i \in A \backslash\{a\} ; j \in B \backslash\{b\}} w_{t}^{a c}(a, j) \cdot e_{t}^{a c}(i, b) \cdot e_{t}^{p c}(i, j) \cdot e^{\left.\left(-\left(\left|t_{a j}-t_{i j}\right|\right) \cdot\right) \cdot \frac{\ln (2)}{T_{1 / 2}}\right)}}{\sum_{i \in A \backslash\{a\}} e_{t}(i, b)}
\end{aligned}
$$

Reciprocity in passive cosponsoring. For passive cosponsorship, reciprocity is measured by the number of times the average active cosponsor of the focal bill $b$ cosponsored a bill introduced by focal member $a$.

The basic closing four-cycle REM statistic for reciprocity in passive cosponsoring sequences is the same as for the active cosponsoring sequence (i.e., Equation 9). However, when incorporating time-weighting using the exponential decay function into the reciprocity statistic, Equation 10 again has to be adapted. As with reciprocity for active cosponsorship, the weighted term $w_{t}^{p c}(i, j)$ would benefit members $i$ that cosponsored bills $j$ later on. To correct this, the term is transformed into a 0/1-dummy and an additional decay function is added to give more weight to events $(i, j)$ where little time has passed since the introduction of bill $j$ at time $t_{a j}$ and $i$ 's cosponsoring event at time $t_{i j}$. Furthermore, the weighted term $w_{t}^{a c}(i, b)$ should not be included, since the time difference between the current event $t$ and the time of event $(i, b)$ (earlier referred to as $t_{e}$ ) is equal to the duration measure (see Equation 4). The incorporation of the duration time into an independent variable violates the exogeneity rule postulated by Lancaster (1990). ${ }^{3}$

Therefore, the reciprocity statistics in both their basic form as well as with time-weighting are formulated as follows:

\footnotetext{
${ }^{3}$ Section 4 in the SI Online discusses this problem in more detail and shows that the inclusion of the duration time into the operationalization of an endogenous network statistic confounds the significance of the effects of the variable in the estimation of the hazard rate.
} 


$$
\begin{aligned}
& \text { reciprocity_passiveCosp }\left(G_{t} ; a, b\right)=\frac{\sum_{\substack{i \in A \\
j \in B}} e_{t}^{a c}(a, j) \cdot e_{t}^{a c}(i, b) \cdot e_{t}^{p c}(i, j)}{\sum_{\substack{i \in A \\
j \in B}} e_{t}(i, b) \cdot e_{t}(i, j)} \\
& \stackrel{\sum_{i \in A \backslash\{a\} ; j \in B \backslash\{b\}} w_{t}^{a c}(a, j) \cdot e_{t}^{a c}(i, b) \cdot e_{t}^{p c}(i, j) \cdot e^{\left(-\left(\left|t_{a j}-t_{i j}\right|\right) \cdot \frac{\ln (2)}{T_{1 / 2}}\right)}}{\sum_{i \in A \backslash\{a\}} e_{t}(i, b)}
\end{aligned}
$$

\section{Data and Variables}

\section{Data}

To analyze how cosponsorship dynamics evolve over time, data on cosponsoring events in the U.S. House of Representatives for the 113th Congress are used. While the analysis is constrained to bills from the energy policy area due to computational restrictions, network effects are calculated over all 123,587 cosponsoring events of the 113th Congress. Data were taken from the webpage of the U.S. Congress ${ }^{4}$. Information gathered includes the original sponsor and the cosponsors of the bill (as well as the corresponding dates), the form, title, full text and policy area of the bill and its status.

In order to preserve the sequence of events, each member's cosponsoring actions were recorded as single events, containing the unique member's name $a \in A$, the ID of the bill $b \in B$ and the day on which the bill was (co-)sponsored $t \in T$. The resulting event sequence contains 123,587 events, involving 352 members of Congress and 6841 bills, spread out over the course of the two years during which the 113th Congress was in session. Federal holidays ${ }^{5}$ were excluded from the event sequence, as well as five weeks of vacation in summer ${ }^{6}$. Weekends were not excluded because several members had records of cosponsoring bills on Saturdays as well as Sundays. The analysis of the event sequence is restricted to all events after June,

\footnotetext{
${ }^{4}$ https: //wWW . congress. gov last accessed March 9, 2016.

${ }^{5}$ Namely New Year's Day, Martin Luther King Day, Inauguration Day, Presidents' Day, Memorial Day, Independence Day, Columbus Day, Veterans Day, Thanksgiving, Christmas

${ }^{6}$ Summer vacation from August 3rd to September 5th in 2013 and August 11th to 7th September in 2014 were excluded.
} 
Table 1: Correlation matrix for reciprocity variables for both the active and passive cosponsoring data sets

\begin{tabular}{|c|c|c|c|c|c|c|c|c|c|c|}
\hline & \multicolumn{5}{|c|}{ Active Cosponsoring } & \multicolumn{5}{|c|}{ Passive Cosponsoring } \\
\hline & (1) & (2) & (3) & (4) & (5) & (1) & (2) & (3) & (4) & (5) \\
\hline (1) Basic statistic & 1 & & & & & 1 & & & & \\
\hline (2) Time-weighted, $T_{1 / 2}=20$ & 0.469 & 1 & & & & 0.558 & 1 & & & \\
\hline (3) Time-weighted, $T_{1 / 2}=50$ & 0.643 & 0.882 & 1 & & & 0.728 & 0.862 & 1 & & \\
\hline (4) Time-weighted, $T_{1 / 2}=100$ & 0.722 & 0.731 & 0.951 & 1 & & 0.787 & 0.698 & 0.941 & 1 & \\
\hline (5) Time-weighted, $T_{1 / 2}=200$ & 0.75 & 0.59 & 0.841 & 0.962 & 1 & 0.769 & 0.56 & 0.813 & 0.956 & 1 \\
\hline
\end{tabular}

4th, 2013. The exclusion of the first 150 event days (corresponding to the date of June, 4th, 2013) is necessary to calibrate the endogenous network statistics and prevent bias due to an underrepresented network of past events $G_{t}$.

For each member of Congress, their party alignment, gender, age, consecutive years of service, district, state and their ideology were assigned to each event involving the respective member. ${ }^{7}$

\section{Independent Variables}

Reciprocity variables for active and passive cosponsoring are operationalized as described in the previous section. The standard closing four-cycle statistic (Equation 9) is calculated for each true and null-event over the past events, represented by $G_{t}$. Additionally, the timeweighted statistic (Equations 13 and 15 for active and passive cosponsoring, respectively) are calculated using four different half-life specifications. The first statistic uses a half-life of 20 event days to discount four-cycles involving bills $j$ that $a$ sponsored in the past. Additional statistics use increased half-life parameters of 50, 100 and 200 event days. As for the second decay-parameter-measuring the influence of a past bill $j$ through the reaction time of member $i$ 's cosponsoring action-is set at 20 event days for all four variables.

Table 1 holds the Pearson correlation matrices for all operationalizations of the reciprocity variables for both the active and passive cosponsorship data sets. The correlations vary from moderate to strong, indicating some variance between the different operationalizations of the

\footnotetext{
${ }^{7}$ Basic demographic information was taken from the Sunlight Foundation (https://sunlightlabs. github. io/congress/index. html\#legislator-spreadsheet, last accessed March 9, 2016). Data on member's ideology is the 1st dimension DW-NOMINATE score of McCarty, Poole and Rosenthal (1997) obtained from http: //www .voteview.com/dwnomin_joint_house_and_senate.htm.
} 
variables. The terms with the smallest half-life parameters of 20 event days measure short-term reciprocity, where favors are remembered more vividly if they occurred in the very recent past. The terms with larger half-life parameters measure reciprocity in the longer run by giving more weight to favors that occurred in the past 3 to 6 months. The basic reciprocity statistic correlates strongly with long-term reciprocity in both data sets.

\section{Control Variables}

Both the logistic regression on the formation of cosponsoring clusters as well as the stratified Cox on the time-to-cosponsoring include a number of control variables. Relational event models only produce unbiased estimates if the endogenous network properties are captured fully though the inclusion of independent or control variables (Butts, 2008, 160). Therefore, several endogenous network statistics are added as control variables.

First, both models include a term measuring previous work relationships by calculating the number of times the focal member has collaborated with one of the other active cosponsors of the focal bill:

$$
\operatorname{previousSponsorship}\left(G_{t} ; a, b\right)=\frac{\sum_{i \in A \backslash\{a\} ; j \in B \backslash\{b\}} w_{t}^{a c}(a, j) \cdot e_{t}^{a c}(i, b) \cdot e_{t}^{a c}(i, j)}{\sum_{i \in A \backslash\{a\}} e_{t}^{a c}(i, b)}
$$

A second term measures cosponsoring similarity between the focal actor and other actors sponsoring the focal bill. The term represents a closing four-cycle, but opposed to the reciprocity statistic, this term measures how often focal actor $a$ and another active sponsor of the bill $i$ have passively cosponsored another bill $j$ :

$$
\text { cosponsoringSimilarity }\left(G_{t} ; a, b\right) \stackrel{\sum_{i \in A \backslash\{a\} ; j \in B \backslash\{b\}} w_{t}^{p c}(a, j) \cdot e_{t}^{a c}(i, b) \cdot e_{t}^{p c}(i, j) \cdot e^{\left(-\left(\left|t_{j}^{a c}-t_{i j}\right|\right) \cdot \frac{\ln (2)}{T_{1 / 2}}\right)}}{\sum_{i \in A \backslash\{a\}} e_{t}^{a c}(i, b)}
$$

A third term measures each focal actor's sponsoring or cosponsoring activity by summing up all past active and passive cosponsoring events where actor $a$ has been involved in and 
weighting them according to how long ago these events took place, giving more weight to more recent events:

$$
\operatorname{activity}\left(G_{t} ; a, b\right)=\sum_{j \in B} w_{t}(a, j)
$$

In the case of active cosponsorship, a shared partner effect measures whether two members are likely to work on a bill together if they have worked with the same people on different bills in the past. The term captures triadic closure in two-mode networks:

$\operatorname{triadicClosure}\left(G_{t} ; a, b\right)=\frac{\sum_{\substack{i_{2} \in A \backslash\left\{i_{1}\right\} ; j_{1} \in B \backslash\left\{j_{2}\right\} \\ i_{1} \in A \backslash\left\{i_{2}\right\} ; j_{2} \in B \backslash\left\{j_{1}\right\}}} w_{t}^{a c}\left(a, j_{1}\right) \cdot e_{t}^{a c}\left(i_{2}, b\right) \cdot e_{t}^{a c}\left(i_{1}, j_{1}\right) \cdot e_{t}^{a c}\left(i_{1}, j_{2}\right) \cdot e_{t}^{a c}\left(i_{2}, j_{2}\right)}{\sum_{i_{2} \in A \backslash\{a\}} e_{t}^{a c}\left(i_{2}, b\right)}$

And in the case of passive cosponsorship, a bill popularity statistic measures the effect of previous passive cosponsoring activity on the focal bill $b$ on a member's time-to-cosponsoring:

$$
\text { billPopularity }\left(G_{t} ; a, b\right)=\sum_{i \in A} w_{t}^{p c}(i, b)
$$

Additionally, both models include homophily and absolute difference terms to capture attribute similarities between the focal actor $a$ and all active sponsors of the focal bill $b$. Several previous studies on legislative cosponsorship have shown that homophily is a powerful force in explaining support patterns among members of Congress (e.g., Craig et al., 2015). Similarities between two members of Congress can strengthen their relationship and create tighter bonds (Lazarsfeld and Merton, 1954). Therefore, controlling for various homophily patterns results in a stronger test for temporal reciprocity patterns in cosponsoring event sequences.

$$
\operatorname{homophily}\left(G_{t}, a, b\right)=\sum_{i \in A} e_{t}(i, b)\left[x_{a}=x_{i}\right]
$$


The attribute homophily term in Equation 21 is used to calculate gender, state and ethnicity homophily as well as neighboring state homophily (the last one using an adapted homophily term).

$$
\text { absoluteDifference }\left(G_{t}, a, b\right)=\sum_{i \in A} e_{t}(i, b) \cdot\left|z_{a}-z_{i}\right|
$$

The absolute difference term in Equation 22 is used to control for ideological differences between the focal actor $a$ and the active cosponsors. Additionally, differences in years of service are controlled for as well.

In addition to the endogenous network statistics and homophily or absolute difference variables, each member's gender, experience-measured in the form of years of service—as well as their deviance from the mean ideology are controlled for. Section 1 in the SI Online shows graphical representations of the endogenous network statistics as well as additional information on all control variables.

\section{Rescaling of Endogenous Network Statistics}

All endogenous network variables that use the exponential decay to control for the passage of time are rescaled by a constant to ensure interpretability of the coefficient sizes. In the case of the reciprocity variables, all variables are rescaled by the constant representing one additional four-cycle, where $w_{t}(a, j)$ occurred 60 days ago and $i$ gave cosponsor support to bill $j 5$ days after $a$ submitted it. Table 2 reports the rescaling constants for all endogenous variables and illustrates what a one unit increase means in terms of network events.

\section{Sensitivity Check Using Two-Mode ERGMs}

Two two-mode ERGMs with custom model terms are estimated on the aggregated active and passive cosponsoring networks to check for reciprocity effects in a cross-sectional setting. The ERGM on active cosponsoring captures each member's tendency to take part in drafting new legislations. The first mode represents 352 members of Congress tying to 125 legislation pro- 
Table 2: Rescaling of regression coefficients: Network scenarios show which network events are necessary to increase an endogenous statistic by one unit for an event involving member $a$ and bill $b$.

\begin{tabular}{|c|c|c|}
\hline Variable & One unit & +1 unit \\
\hline Reciprocity: received cosponsor support & 0.0036 & $\begin{array}{l}\text { sponsored a bill } 60 \text { days ago and received cosponsor support from average other cosponsor } 5 \text { days after } a \\
\text { submitted bill. Unit increase varies for different half-life specifications: } T_{1 / 2}=20=+0.0036, T_{1 / 2}=50= \\
+0.0051, T_{1 / 2}=100=+0.0038, T_{1 / 2}=200=+0.0024\end{array}$ \\
\hline Inertia: previously sponsored together & 0.0043 & sponsored together 60 days ago \\
\hline Similarity: Cosponsored the same bills & 0.0040 & $\begin{array}{l}\text { sponsored a bill } 60 \text { days ago and received cosponsor support from average other current sponsor } 2 \text { days after } \\
\text { submission }\end{array}$ \\
\hline Shared partners & 0.6250 & having 2 sponsors in common with average current sponsor (engaged with shared sponsors 60 and 20 days ago) \\
\hline Member activity - active cosponsoring & 0.0245 & having sponsored 2 bills, 30 days ago \\
\hline Member activity - passive cosponsoring & 0.1225 & having (co)-sponsored 5 bills 10 days ago \\
\hline Short-term bill popularity & 0.1834 & current bill got cosponsored 1 day ago \\
\hline Bill popularity among ideologically different members & 0.0367 & current bill got cosponsored 1 day ago by member with differing ideology of 0.2 \\
\hline
\end{tabular}

posals. All endogenous model terms used in the REM (except activity) are re-built as custom two-mode ERGM terms using the full data on cosponsoring events for the entire duration of the 113th Congress. The custom terms do not incorporate time, but rather reflect raw frequencies. Control variables are adapted and included as well.

The ERGM on passive cosponsoring captures each member's tendency to cosponsor an introduced legislation. The first mode is populated by 352 members of Congress, tying to 64 bills $^{8}$. The ERGM does not capture time-to-cosponsoring, but rather the singular decision to cosponsor an introduced bill. As such, the results from the ERGM and the REM on passive cosponsorship are not comparable and the results of the ERGM are therefore only included in Section 2 of the SI Online.

For additional information on the two-mode ERGMs, the model terms or in-depth interpretation of the results, please refer to Section 2 of the SI Online.

\section{Results}

\section{Results on Active Cosponsorship}

Table 3 holds the results of the logisitc regression on the emergence of active cosponsorship clusters over time. Model (1) shows the results from the cross-sectional two-mode ERGM on active cosponsorship. Models (2) to (6) show results from the REM using differently weigthed

\footnotetext{
${ }^{8}$ The number is reduced as only 64 of the 125 energy bills showed any passive cosponsoring activity.
} 
reciprocity variables whilst controlling for other endogenous network statistics, homophily variables and sender-attribute-based controls. Model (7) includes an interaction term of party alignment on reciprocity.

Results indicate that reciprocity does play a part in the emergence of new collaboration clusters, in the sense that previous cosponsorship support leads to future collaboration on new bills. However, the temporal statistics allow for more nuanced interpretations. Both the ERGM as well as the generally scaled reciprocity variable show positive effects (see Models (1) and (2)). But these effects are only mirrored in the time-weighted statistics, if the half-life parameter is set to 200 event days - essentially opening up the network of past events to incorporate even temporally distant sponsoring events. The distinction between the reported effects of the time-weighted statistics becomes evident, when examining an interaction effect with party alignment. The REM with scaled reciprocity and time-weighted reciprocity with short half-life parameters of 20 or 50 report a significant and negative reciprocity effect for Democratic members and a significant and positive effect of Reciprocity for Republican members of Congress. Table 3 reports the interaction model with the best fit according to its Bayesian information criterion (BIC) in model (7). Please refer to Table 3 in the SI Online for complete reports on the results of the interaction effects on all reciprocity variables.

The significant and positive effects for Republican members of Congress indicates that previous cosponsoring support issued within the past few months has a strong effect on future collaborations on new bills. Interestingly, Democratic members do not start working with members that have recently expressed support for their work.

All models control for a wide range of endogenous network statistics, homophily variables and other control variables. Collaborations show a strong effect towards inertia, where members who have previously sponsored a bill together are more likely to sponsor a bill together again. Previous studies on legislative cosponsorship have stressed the importance of triadic closure (Cranmer and Desmarais, 2011). These results cannot be replicated under the present specifications and using the data on cosponsoring in the 113th U.S. Congress. Triadic closure even has a negative and significant coefficient. Having two more sponsors in common 
with the average other active cosponsor of the current bill negatively affects the odds of being involved in the preparation of the current bill. However, homophily tendencies in legislative collaborations hold under the REMs. Ideological differences, years of service, same state and neighboring state all show positive effects on collaboration clusters (note that ideological differences are measured using an absolute difference term and a negative coefficient indicates that as ideological differences between members increases, chances of collaboration decrease).

Other than its relatively low explanation power, as measured by McFadden's pseudo $R^{2}$, the models are relatively stable and compare to effects found in the cross-sectional ERGM. Figure 6 depicts precision-recall and receiver operating characteristic curves for the six different models that include the interaction effect with party alignment. While models including endogenous network terms outperform models without, the predictive power of the models are relatively similar, with the time-weighted model using a half-life of 50 event days slightly outperforming the others.

Overall the different models using varied reciprocity statistics give a good overview over the temporal dynamics of reciprocity in cosponsorship sequences. Whereas Republican members of Congress are spurred to collaborate with members from whom they recently received favors, Democratic members show reversed effects, controlling for a broad selection of endogenous and exogenous effects.

\section{Results on Passive Cosponsorship}

Table 4 reports the result of the stratified Cox regression on time-to-cosponsoring. The models capture which factors hasten a member's expression of support for an introduced bill. A positive coefficient indicates shorter survival time or a higher hazard of event occurrence. ${ }^{9}$

\footnotetext{
${ }^{9}$ For each effect, the percentage change in the hazard rate can be calculated via$$
\% \Delta h(t)=\left(\frac{e^{\beta\left(x_{i}=X_{1}\right)}-e^{\beta\left(x_{i}=X_{2}\right)}}{e^{\beta\left(x_{i}=X_{2}\right)}}\right) \cdot 100,
$$

where $\beta$ represents the beta coefficient of a given covariate $x_{i}$, and $X_{1}$ and $X_{2}$ represent two values of the covariate (Box-Steffensmeier and Jones, 2004, 60).
} 
Table 3: Results of the logistic regression on active cosponsorship

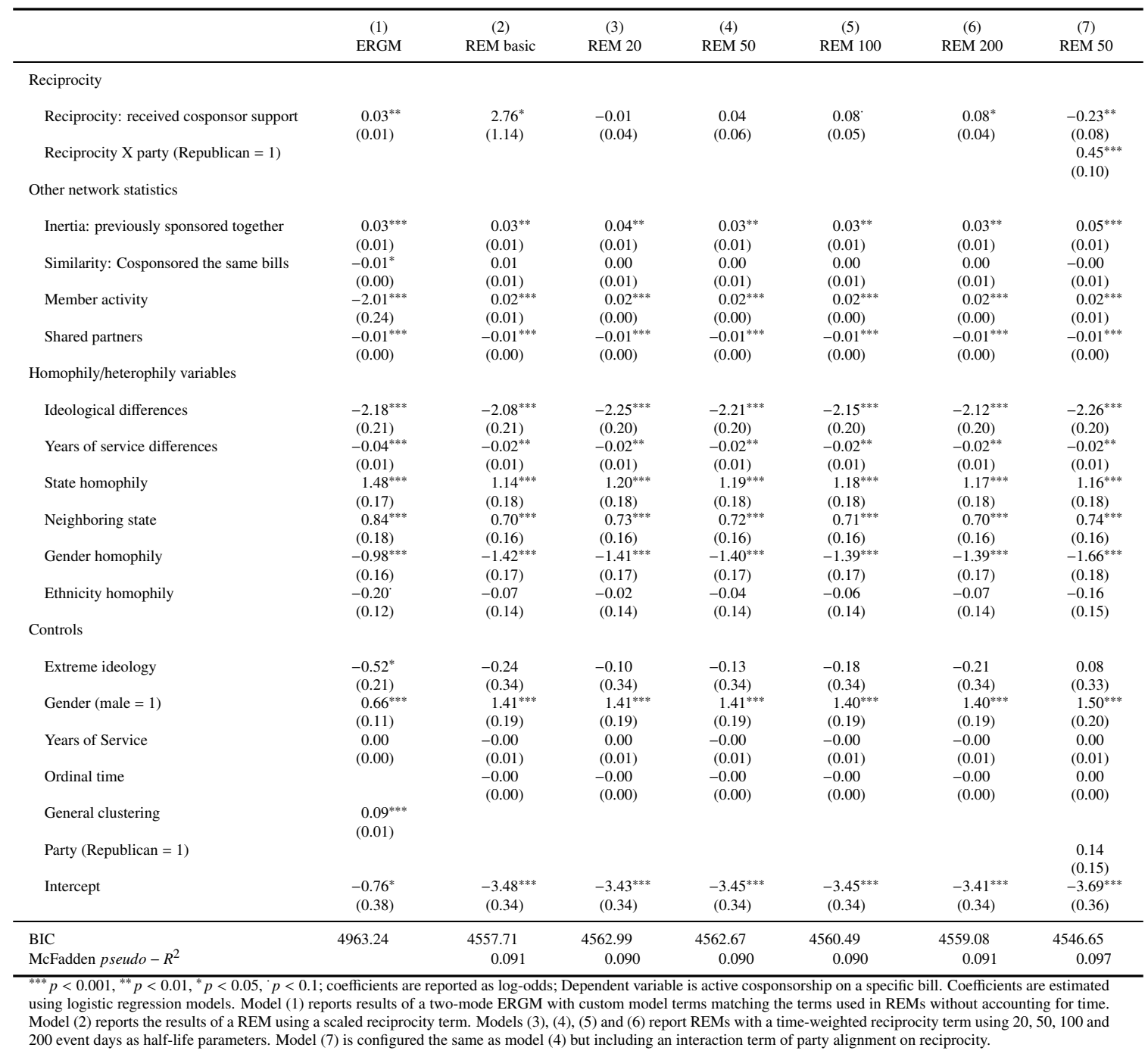




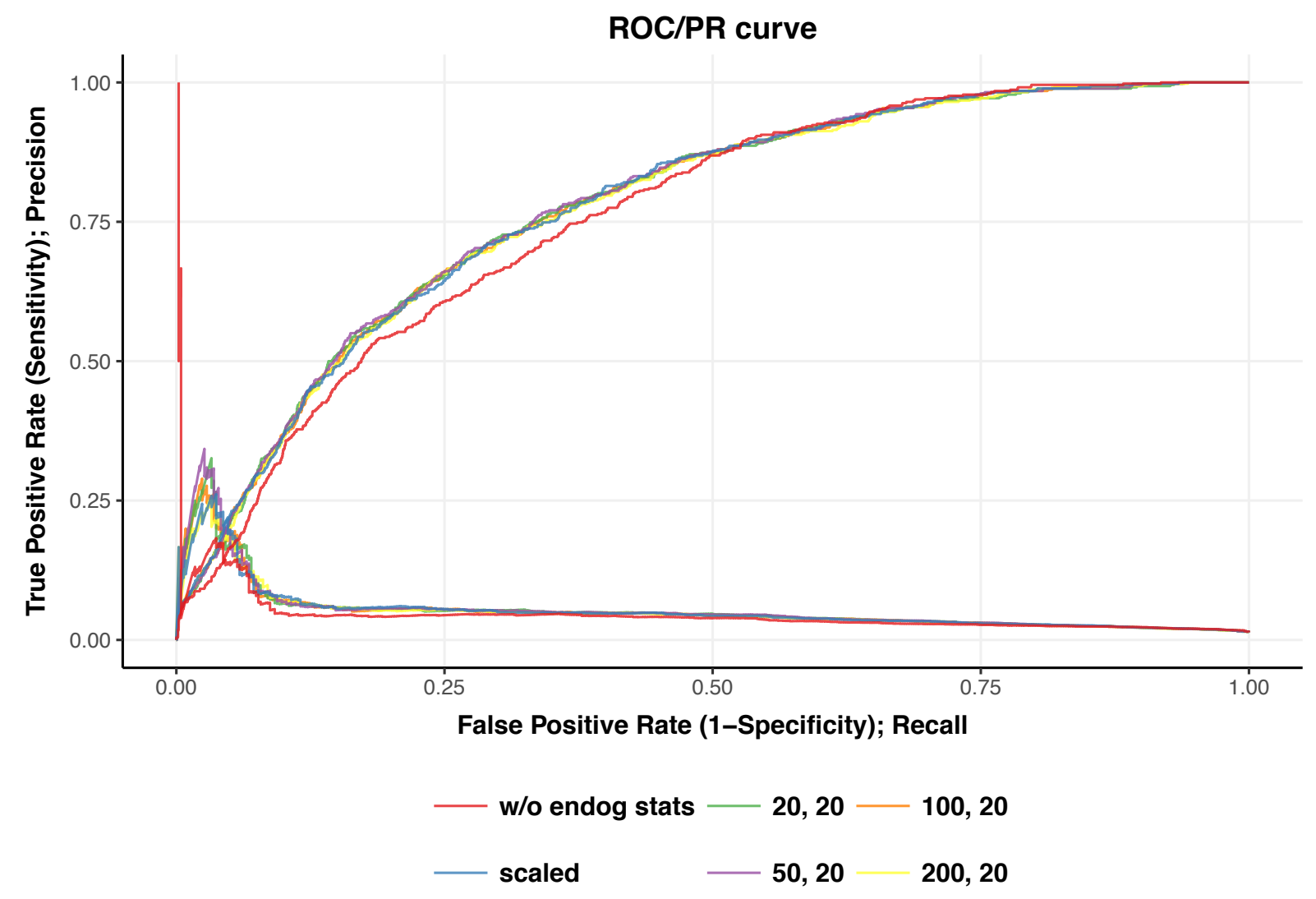

Figure 6: Precision-Recall and Receiver Operating Characteristics curves for logistic regression models on active cosponsorship cluster formations over time. Red line represents a REM without endogenous network statistics; blue line represents a REM with a scaled reciprocity term; green, violet, orange and yellow lines represent REMs with a time-weighted reciprocity term using 20, 50, 100 and 200 event days as half-life parameters, respectively. 
Models (1) to (5) show results with different operationalizations of the temporal reciprocity statistic. Model (6) includes an interaction term for reciprocity on party alignment.

The main hypothesis with regard to passive cosponsoring events was that recent favors are repaid in kind with immediate (or temporally close) support on one of the previous supporters' bills. However, this does not seem to be the case. Previous support does not expedite new announcements of support, in fact, they seem to even deter from it.

The ERGM on passive cosponsorship reports a highly significant and positive effect for reciprocity (see Table 2 in the SI Online), indicating that members of Congress do tend to reciprocate previous support. However, that reciprocation tends to be issued later in time, when the bill has already been introduced and previous favors are further in the past. An interaction term with party alignment in model (7) indicates that Democratic members are responsible for the negative correlation with the event rate. These results raise the question if reciprocity really guides this passive cosponsorship behavior, as assumed from the cross-sectional ERGM results. Members do not react to favors by reciprocating them as soon as possible. The stratified Cox compares the reciprocity statistics for true-events with the statistic for the null-events at each point in time, determining whether or not a higher reciprocity statistic-increased by receiving a favor over the past few event days-affects the hazard of event occurrence. Results indicate that Republican members do not react to receiving favors and Democratic members are negatively affected by receiving a favor in the past event days.

Results also show some sensitivity to different half-life parameter specifications. The reciprocity effect does not show any significant effects for half-parameters of 20 event days (in the model including an interaction effect with party alignment, see Table 5 in the SI Online). The affect only becomes negative under the basic reciprocity specification without time-weighting or with a half-life parameter of 50 or higher. These results do not support the presumption that receiving a favor from another member of Congress is reciprocated soon after. Rather, members seem to take time to deliberate which bill to sign and when.

As for the control variables, having cosponsored a lot of the same bills does positively affect the hazard of event occurrence, as does short-term bill popularity. Short-term bill popularity 
Table 4: Results of the Cox regression on time-to-passive-cosponsorship

\begin{tabular}{|c|c|c|c|c|c|c|}
\hline & $\begin{array}{c}(1) \\
\text { REM basic }\end{array}$ & $\begin{array}{c}(2) \\
\text { REM } 20\end{array}$ & $\begin{array}{c}\text { (3) } \\
\text { REM } 50\end{array}$ & $\begin{array}{c}(4) \\
\text { REM } 100\end{array}$ & $\begin{array}{c}\text { (5) } \\
\text { REM } 200\end{array}$ & $\begin{array}{c}(6) \\
\text { REM } 200\end{array}$ \\
\hline \multicolumn{7}{|l|}{ Reciprocity } \\
\hline Reciprocity: received cosponsor support & $\begin{array}{c}-1.49 \\
(1.39)\end{array}$ & $\begin{array}{c}-0.04 \\
(0.05)\end{array}$ & $\begin{array}{c}-0.17^{*} \\
(0.08)\end{array}$ & $\begin{array}{c}-0.18^{* *} \\
(0.07)\end{array}$ & $\begin{array}{c}-0.15^{* * *} \\
(0.05)\end{array}$ & $\begin{array}{c}-0.22^{* * *} \\
(0.06)\end{array}$ \\
\hline Reciprocity X party (Republican $=1$ ) & & & & & & $\begin{array}{c}0.11 \\
(0.09)\end{array}$ \\
\hline \multicolumn{7}{|l|}{ Other network statistics } \\
\hline Inertia: previously sponsored together & $\begin{array}{c}-0.01 \\
(0.02)\end{array}$ & $\begin{array}{c}-0.02 \\
(0.02)\end{array}$ & $\begin{array}{c}-0.01 \\
(0.02)\end{array}$ & $\begin{array}{c}0.00 \\
(0.02)\end{array}$ & $\begin{array}{c}0.00 \\
(0.02)\end{array}$ & $\begin{array}{c}0.01 \\
(0.02)\end{array}$ \\
\hline Similarity: Cosponsored the same bills & $\begin{array}{l}0.06^{* *} \\
(0.02)\end{array}$ & $\begin{array}{l}0.06^{* * *} \\
(0.02)\end{array}$ & $\begin{array}{l}0.07^{* * * *} \\
(0.02)\end{array}$ & $\begin{array}{l}0.07^{* * *} \\
(0.02)\end{array}$ & $\begin{array}{l}0.07^{* * *} \\
(0.02)\end{array}$ & $\begin{array}{l}0.08^{* * *} \\
(0.02)\end{array}$ \\
\hline Member activity & $\begin{array}{c}0.04 \\
(0.03)\end{array}$ & $\begin{array}{c}0.04 \\
(0.03)\end{array}$ & $\begin{array}{c}0.04 \\
(0.03)\end{array}$ & $\begin{array}{c}0.04 \\
(0.03)\end{array}$ & $\begin{array}{c}0.04 \\
(0.03)\end{array}$ & $\begin{array}{c}0.05 \\
(0.03)\end{array}$ \\
\hline Short-term bill popularity & $\begin{array}{l}0.39^{* * *} \\
(0.05)\end{array}$ & $\begin{array}{l}0.38^{* * *} \\
(0.05)\end{array}$ & $\begin{array}{l}0.39^{* * *} \\
(0.05)\end{array}$ & $\begin{array}{l}0.39^{* * *} \\
(0.05)\end{array}$ & $\begin{array}{l}0.39^{* * *} \\
(0.05)\end{array}$ & $\begin{array}{l}0.38^{* * *} \\
(0.05)\end{array}$ \\
\hline \multicolumn{7}{|l|}{ Homophily/heterophily variables } \\
\hline Ideological differences & $\begin{array}{c}-0.90^{* *} \\
(0.31)\end{array}$ & $\begin{array}{l}-0.83^{* *} \\
(0.29)\end{array}$ & $\begin{array}{c}-0.88^{* *} \\
(0.29)\end{array}$ & $\begin{array}{c}-0.93^{* *} \\
(0.29)\end{array}$ & $\begin{array}{l}-0.98^{* * *} \\
(0.30)\end{array}$ & $\begin{array}{c}-0.80^{*} \\
(0.33)\end{array}$ \\
\hline State homophily & $\begin{array}{l}1.39^{* * *} \\
(0.21)\end{array}$ & $\begin{array}{l}1.40^{* * * *} \\
(0.21)\end{array}$ & $\begin{array}{l}1.44^{* * * *} \\
(0.20)\end{array}$ & $\begin{array}{l}1.42^{* * * *} \\
(0.20)\end{array}$ & $\begin{array}{l}1.38^{* * *} \\
(0.21)\end{array}$ & $\begin{array}{l}1.40^{* * * *} \\
(0.21)\end{array}$ \\
\hline Neighboring state & $\begin{array}{c}0.22 \\
(0.27)\end{array}$ & $\begin{array}{c}0.17 \\
(0.26)\end{array}$ & $\begin{array}{c}0.21 \\
(0.26)\end{array}$ & $\begin{array}{c}0.24 \\
(0.26)\end{array}$ & $\begin{array}{c}0.25 \\
(0.26)\end{array}$ & $\begin{array}{c}0.17 \\
(0.28)\end{array}$ \\
\hline Gender homophily & $\begin{array}{l}-1.64^{* *} \\
(0.61)\end{array}$ & $\begin{array}{l}-1.68^{* *} \\
(0.61)\end{array}$ & $\begin{array}{l}-1.63^{* *} \\
(0.59)\end{array}$ & $\begin{array}{l}-1.58^{* *} \\
(0.59)\end{array}$ & $\begin{array}{l}-1.56^{* * *} \\
(0.58)\end{array}$ & $\begin{array}{l}-1.68^{* *} \\
(0.58)\end{array}$ \\
\hline Years of service differences & $\begin{array}{c}0.01 \\
(0.01)\end{array}$ & $\begin{array}{c}0.01 \\
(0.01)\end{array}$ & $\begin{array}{c}0.01 \\
(0.01)\end{array}$ & $\begin{array}{c}0.01 \\
(0.01)\end{array}$ & $\begin{array}{c}0.01 \\
(0.01)\end{array}$ & $\begin{array}{c}0.01 \\
(0.01)\end{array}$ \\
\hline \multicolumn{7}{|l|}{ Additional controls } \\
\hline Extreme ideology & $\begin{array}{l}1.59^{* * *} \\
(0.33)\end{array}$ & $\begin{array}{l}1.56^{* * * *} \\
(0.33)\end{array}$ & $\begin{array}{l}1.56^{* * *} \\
(0.33)\end{array}$ & $\begin{array}{l}1.59^{* * *} \\
(0.33)\end{array}$ & $\begin{array}{l}1.63^{* * *} \\
(0.33)\end{array}$ & $\begin{array}{l}1.69^{* * *} \\
(0.33)\end{array}$ \\
\hline Gender $($ male $=1)$ & $\begin{array}{l}1.62^{* *} \\
(0.60)\end{array}$ & $\begin{array}{l}1.64^{* *} \\
(0.60)\end{array}$ & $\begin{array}{l}1.59^{* *} \\
(0.59)\end{array}$ & $\begin{array}{l}1.53^{* *} \\
(0.58)\end{array}$ & $\begin{array}{l}1.50^{* *} \\
(0.58)\end{array}$ & $\begin{array}{l}1.50^{* * *} \\
(0.57)\end{array}$ \\
\hline Years of Service & $\begin{array}{c}0.00 \\
(0.01)\end{array}$ & $\begin{array}{c}0.00 \\
(0.01)\end{array}$ & $\begin{array}{c}0.00 \\
(0.01)\end{array}$ & $\begin{array}{c}0.00 \\
(0.01)\end{array}$ & $\begin{array}{c}0.01 \\
(0.01)\end{array}$ & $\begin{array}{c}0.00 \\
(0.01)\end{array}$ \\
\hline Party (Republican = 1) & & & & & & $\begin{array}{c}0.16 \\
(0.22)\end{array}$ \\
\hline AIC & 3323.23 & 3323.66 & 3320.04 & 3317.64 & 3316.37 & 3314.18 \\
\hline McFadden pseudo $-R^{2}$ & 0.075 & 0.075 & 0.076 & 0.077 & 0.077 & 0.079 \\
\hline
\end{tabular}

is an interesting variable as it is measured with a very small half-life parameter of only three event days to capture previous actions on the focal bill just days before member $a$ decides to cosponsor $b$. Closer analysis of the effect (reported in Section 5 in the SI Online) indicates that bill popularity is mostly driven by state- and neighboring state homophily. If a member from the same or a neighboring state very recently decided to cosponsor a bill, then the hazard of signing the bill increases drastically. Furthermore, sharing similar ideologies with the original cosponsors does speed up cosponsoring support, as does knowing that many members among the active cosponsors are from the same state. 


\section{Conclusion}

Relational event models are a powerful tool in examining structural properties of network evolution. This especially holds true for two-mode networks because unlike two-mode network snapshots, two-mode event sequences cannot easily be transformed into one-mode sequences.

This paper used two-mode cosponsorship event sequences to determine to what extent cosponsoring activities are guided by reciprocity. Different operationalizations of temporal reciprocity statistics were used to assess in which time frames reciprocity reports the most powerful effects. Results indicate that Republican members reciprocate previous support most vigorously if they received cosponsoring support within the past few months by working together on new bills. Democratic members, on the other hand, exhibited negative effects of reciprocity on the formation of new collaboration clusters. This strong interaction effect is intriguing and could be examined further-for instance through modeling additional information on the target nodes. The formation of new collaboration clusters over time was analyzed using actor-centered network statistics, such as triadic closure or homophily effects. Future research could include additional information on the second mode - the bills - to gain further insights into which bills Republican (or Democratic) members tend (not) to reciprocate previous support with and what their characteristics entail.

A second analysis was made to gain more information on reciprocity effects on passive cosponsorship. Passive cosponsorship entails significantly less costs (i.e., by not taking up a lot of time or resources of a member of Congress) than actively sponsoring a bill could. Previous results, as well as a two-mode ERGM on passive cosponsorship indicate ample evidence of reciprocity effects for passive cosponsorship. However, when analyzing the timing of these support statements, results indicated that reciprocity does not expedite cosponsoring events - indeed, for Democratic members, previously received support correlates with longer time-to-cosponsoring. The result shows that modeling time-since-event-occurrence could yield interesting new insights into how human behavior adapts to changes in their surrounding net- 
work. In the case of sponsorship, members are not spurred to reciprocate support soon after they received it.

It is important to note, however, that cosponsoring data has been widely criticized to incorporate too much noise and therefore produce biased results. Future research should use different sources to examine Congressional collaboration. For instance, Desmarais et al. (2015) recently used Senate press events instead of cosponsoring events to measure legislative collaborations. Rather than aggregating the press events as the authors have done, the sequence of events could be examined using a logistic regression as presented in this paper.

Methodologically, this paper proposed two different estimation strategies to analyze event sequences with unique target nodes or event sequences that show inherent time-dependence in their target node set composition. Figure 7 provides an overview over the different relational event models in use for modeling two-mode event sequences.

Exact-time two-mode event sequences with a time-independent target mode can be treated like one-mode exact-time sequences. As such, the evolution of events can be examined by analyzing factors that effect the time-to-next-event, or follow-up time. A political debate can serve as an example. An exact-time REM of a political debate could examine which political actors speak out next in a debate to postulate their preferred policy solution (Leifeld, 2017). Contrarily, whenever the target mode in a two-mode event sequence shows an inherent timedependence, factors that affect the reaction time until an event occurs may be analyzed. One example of another application of such a model would be to examine which endogenous and exogenous factors play a role in the vetoing timing or which factors spurr an actor to sanction another actor (Cranmer, Heinrich and Desmarais, 2014).

Discrete-time two-mode event sequences can be modeled using stratified Cox regression models with times set to a constant (or conditional logistic regressions) (Gail, Lubin and Rubinstein, 1980; Allison, 1982). As such, the models estimate the likelihood that an event occurs, given it has not occurred yet. However, if the target nodes in the sequence are unrepeatable, this paper has shown that stratified Cox regression (or conditional logistic regression) models fail due to a non-specifiable risk set. Alternatively, the clustering of sender nodes surrounding 
unrepeatable targets can be examined using logistic regression whilst controlling for all possible endogenous network effects. One example of another application of such a model would be to analyze the formation of new scientific collaboration teams over time by examining which network dependencies matter in the formation of new scientific authorship teams.

There are several limitations to two-mode REMs. First, REMs demand a specific data structure with a sender mode, a target mode and an ordered or exact-time event sequence. Second, given that event networks are prone to include thousands of events over a long time period, the computation of the endogenous network statistics can become computationally intensive. One solution to this problem is sampling from within the sequence to reduce computation time. $\mathrm{Vu}$, Pattison and Robins (2015), for instance, propose a nested case-control sampling approach to deal with large risk set sizes and temporal network statistics. More research on the effects of sampling is needed. Third, REMs, much like other regression models, may suffer from omitted variable bias if the endogenous network effects are not specified sufficiently or correctly (Butts, 2008, 160). A good set of measures should be built to assess goodness-of-fit for modeled event sequences. Such goodness-of-fit measures could help with endogenous network term selection and further clarify which endogenous effects are indispensable. These last two limitations pose interesting problems for future research in computational social sciences.

There is little doubt that with greater availability of time-stamped or time-ordered network data, relational event models are becoming increasingly important in modeling the structural changes and social processes of networks over time and can thus help strengthen temporal assumptions of how networks change and adapt over time (de Nooy, 2015). This paper offers new insights into favor trading in congressional collaborations and raises new questions on how and particularly when the norm of reciprocity is exercised. The specifications for relational event models are continuously adapted and expanded and future research on dynamic network evolutions will undoubtably provide us with new insights into how human behavior evolves over time. 


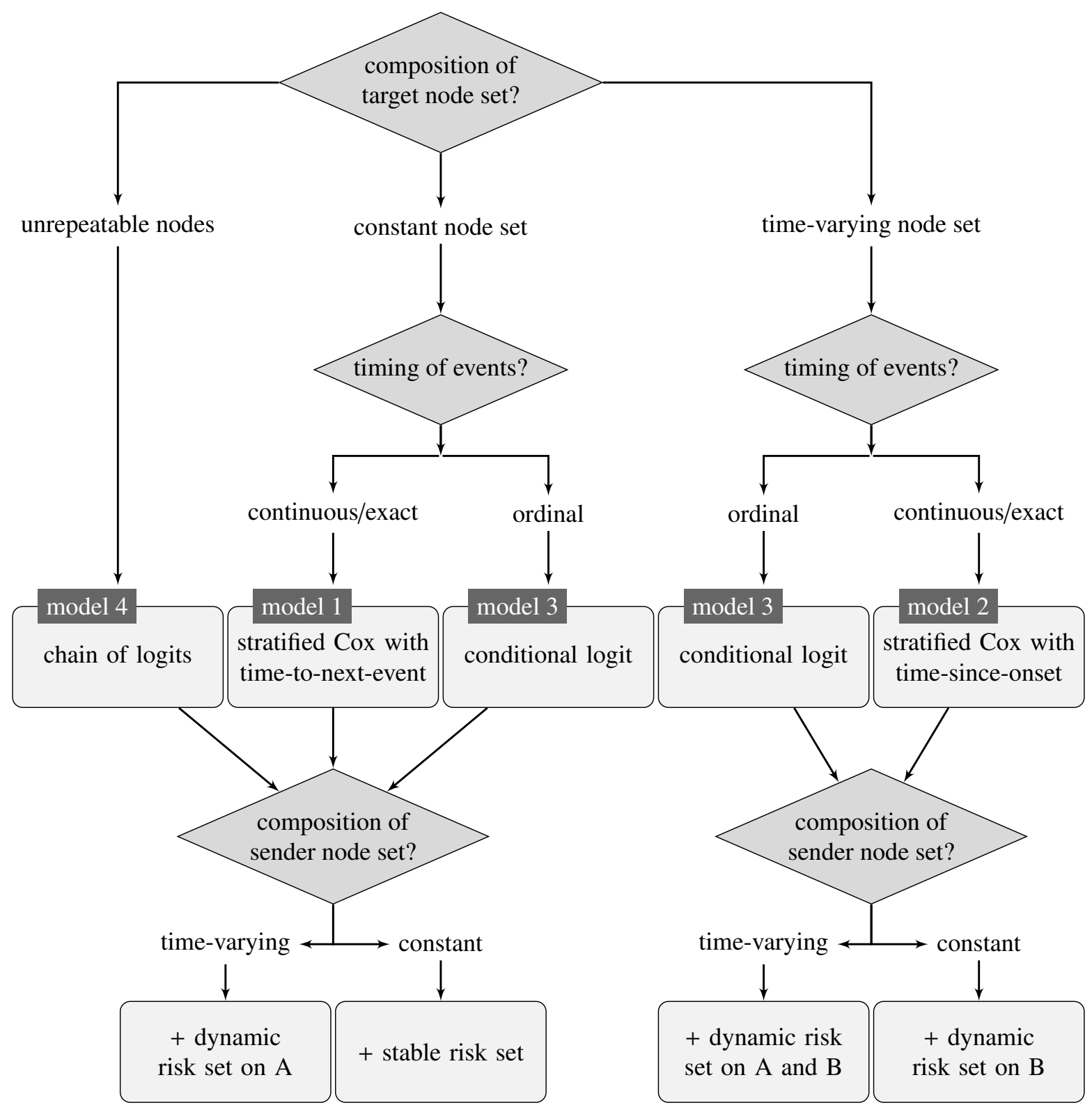

Figure 7: Decision tree to determine model choice and risk-set specifications for two-mode REMs 


\section{References}

Allison, Paul D. 1982. "Discrete-time methods for the analysis of event histories." Sociological methodology 13(1):61-98.

Ammann, Rudolf. 2011. "Reciprocity, social curation and the emergence of blogging: A study in community formation." Procedia-Social and Behavioral Sciences 22:26-36.

Axelrod, Robert M. 2006. The evolution of cooperation. New York: Basic books.

Barnello, Michelle A and Kathleen A Bratton. 2007. "Bridging the gender gap in bill sponsorship." Legislative Studies Quarterly 32(3):449-474.

Berg, Joyce, John Dickhaut and Kevin McCabe. 1995. "Trust, reciprocity, and social history." Games and economic behavior 10(1):122-142.

Borgatti, Stephen P and Martin G Everett. 1997. "Network analysis of 2-mode data." Social networks 19(3):243-269.

Box-Steffensmeier, Janet M and Bradford S Jones. 2004. Event history modeling: A guide for social scientists. Cambridge: Cambridge University Press.

Bratton, Kathleen A and Stella M Rouse. 2011. "Networks in the legislative arena: How group dynamics affect cosponsorship.” Legislative Studies Quarterly 36(3):423-460.

Broccatelli, Chiara, Martin Everett and Johan Koskinen. 2016. "Temporal dynamics in covert networks." Methodological Innovations 9:1-14.

Butts, Carter T. 2008. "A relational event framework for social action.” Sociological Methodology 38(1):155-200.

Campbell, James E. 1982. "Cosponsoring legislation in the US Congress." Legislative Studies Quarterly 7:415-422. 
Conaldi, Guido and Alessandro Lomi. 2013. “The dual network structure of organizational problem solving: A case study on open source software development." Social Networks $35(2): 237-250$.

Cook, Karen S, Coye Cheshire, Eric RW Rice and Sandra Nakagawa. 2013. Social exchange theory. In Handbook of social psychology. Springer pp. 61-88.

Craig, Alison, Skyler J Cranmer, Bruce A Desmarais, Christopher J Clark and Vincent G Moscardelli. 2015. "The Role of Race, Ethnicity, and Gender in the Congressional Cosponsorship Network." arXiv preprint arXiv:1512.06141 .

Cranmer, Skyler J and Bruce A Desmarais. 2011. "Inferential network analysis with exponential random graph models." Political Analysis 19(1):66-86.

Cranmer, Skyler J, Tobias Heinrich and Bruce A Desmarais. 2014. "Reciprocity and the structural determinants of the international sanctions network." Social Networks 36:5-22.

De Nooy, Wouter. 2011. "Networks of action and events over time. A multilevel discrete-time event history model for longitudinal network data." Social Networks 33(1):31-40.

de Nooy, Wouter. 2015. "Structure from interaction events.” Big Data E Society 2(2):1-4.

De Nooy, Wouter and Jan Kleinnijenhuis. 2013. "Polarization in the media during an election campaign: A dynamic network model predicting support and attack among political actors." Political communication 30(1):117-138.

Desmarais, Bruce A and Skyler J Cranmer. 2012. "Statistical mechanics of networks: Estimation and uncertainty." Physica A: Statistical Mechanics and its Applications 391(4):18651876.

Desmarais, Bruce A, Vincent G Moscardelli, Brian F Schaffner and Michael S Kowal. 2015. "Measuring legislative collaboration: The Senate press events network." Social Networks 40:43-54. 
DuBois, Christopher, Carter Butts and Padhraic Smyth. 2013. Stochastic blockmodeling of relational event dynamics. In Proceedings of the Sixteenth International Conference on Artificial Intelligence and Statistics. pp. 238-246.

Dufwenberg, Martin and Georg Kirchsteiger. 2004. "A theory of sequential reciprocity." Games and economic behavior 47(2):268-298.

Emerson, Richard M. 1976. "Social exchange theory." Annual review of sociology 2(1):335362.

Ergün, Güler. 2002. "Human sexual contact network as a bipartite graph.” Physica A: Statistical Mechanics and its Applications 308(1):483-488.

Everard, Andrea and Raymond Henry. 2002. "A social network analysis of interlocked directorates in electronic commerce firms." Electronic Commerce Research and Applications $1(2): 225-234$.

Everett, Martin G and Stephen P Borgatti. 2013. "The dual-projection approach for two-mode networks." Social Networks 35(2):204-210.

Falk, Armin and Urs Fischbacher. 2006. "A theory of reciprocity." Games and economic behavior 54(2):293-315.

Faust, Katherine, Karin E Willert, David D Rowlee and John Skvoretz. 2002. "Scaling and statistical models for affiliation networks: patterns of participation among Soviet politicians during the Brezhnev era." Social Networks 24(3):231-259.

Fowler, James H. 2006. "Connecting the Congress: A study of cosponsorship networks." Political Analysis 14(4):456-487.

Friedkin, Noah E. 2004. “Social cohesion.” Annu. Rev. Sociol. 30:409-425.

Gail, Michell H., Jay H. Lubin and Lawrence V. Rubinstein. 1980. "Likelihood Calculations for Matched Case-Control Studies and Survival Studies with Tied Death Times." Biometrika 68:703-707. 
Gouldner, Alvin W. 1960. “The norm of reciprocity: A preliminary statement." American Sociological Review 25(2):161-178.

Guillaume, Jean-Loup and Matthieu Latapy. 2006. "Bipartite graphs as models of complex networks." Physica A: Statistical Mechanics and its Applications 371(2):795-813.

Harrigan, Nicholas and Janice Yap. 2017. "Avoidance in negative ties: Inhibiting closure, reciprocity, and homophily." Social Networks 48:126-141.

Hojnacki, Marie and David C Kimball. 1999. “The who and how of organizations' lobbying strategies in committee." The Journal of Politics 61(04):999-1024.

Ikkink, Karen Klein and Theo Van Tilburg. 1999. "Broken ties: Reciprocity and other factors affecting the termination of older adults' relationships.” Social networks 21(2):131-146.

Kessler, Daniel and Keith Krehbiel. 1996. "Dynamics of cosponsorship.” American Political Science Review 90(03):555-566.

Kirkland, Justin H. 2011. "The relational determinants of legislative outcomes: Strong and weak ties between legislators." The Journal of Politics 73(3):887-898.

Kirkland, Justin H and Justin H Gross. 2014. "Measurement and theory in legislative networks: The evolving topology of Congressional collaboration.” Social Networks 36:97-109.

Kitts, James A, Alessandro Lomi, Daniele Mascia, Francesca Pallotti, Eric Quintane et al. 2016. "Investigating the temporal dynamics of inter-organizational exchange: Patient transfers among Italian hospitals." American Journal of Sociology .

Lancaster, Tony. 1990. The econometric analysis of transition data. Cambridge: Cambridge University Press.

Latapy, Matthieu, Clémence Magnien and Nathalie Del Vecchio. 2008. "Basic notions for the analysis of large two-mode networks." Social networks 30(1):31-48. 
Lazarsfeld, P.F. and R.K. Merton. 1954. Friendship as a social process. In Freedom and Control in Modern Society, ed. M. Berger, T. Abel and C.S. Page. 18 ed. New York: Van Nostrand pp. 18-66.

Lee, Sang Hoon, José Manuel Magallanes and Mason A Porter. 2015. “Time-dependent community structure in legislation cosponsorship networks in the Congress of the Republic of Peru." arXiv preprint arXiv:1510.01002 .

Leenders, Roger Th AJ, Noshir S Contractor and Leslie A DeChurch. 2016. "Once upon a time: Understanding team processes as relational event networks." Organizational Psychology Review 6(1):92-115.

Leifeld, Philip. 2017. Discourse Network Analysis: Policy Debates as Dynamic Networks. In The Oxford Handbook of Political Networks, ed. Jennifer N. Victor, Mark N. Lubell and Alexander H. Montgomery. Oxford: Oxford University Press chapter 25.

Leifeld, Philip and Laurence Brandenberger. 2017. "Endogenous Coalition Formation in Policy Debates.".

Lerner, Jürgen, Margit Bussmann, Tom AB Snijders and Ulrik Brandes. 2013. "Modeling frequency and type of interaction in event networks." Corvinus Journal of Sociology and Social Policy (1):3-32.

Lerner, Jürgen, Natalie Indlekofer, Bobo Nick and Ulrik Brandes. 2013. "Conditional independence in dynamic networks." Journal of Mathematical Psychology 57(6):275-283.

Liang, Hai. 2014. "The organizational principles of online political discussion: A relational event stream model for analysis of web forum deliberation." Human Communication Research 40(4):483-507.

Malang, Thomas, Laurence Brandenberger and Philip Leifeld. 2017. "Networks and Social Influence in European Legislative Politics.”. 
Maoz, Zeev, Ranan D Kuperman, Lesley Terris and Ilan Talmud. 2006. "Structural equivalence and international conflict: A social networks analysis." Journal of Conflict Resolution 50(5):664-689.

Mayhew, David R. 1974. Congress: The electoral connection. New Haven, CT: Yale University Press.

McCarty, Nolan M, Keith T Poole and Howard Rosenthal. 1997. Income redistribution and the realignment of American politics. Washington, DC: AEI Press.

Melamed, David and Brent Simpson. 2016. "Strong ties promote the evolution of cooperation in dynamic networks." Social Networks 45:32-44.

Mercken, Liesbeth, Tom AB Snijders, Christian Steglich, Erkki Vartiainen and Hein De Vries. 2010. "Dynamics of adolescent friendship networks and smoking behavior." Social Networks 32(1):72-81.

Molm, Linda D, David R Schaefer and Jessica L Collett. 2007. "The value of reciprocity." Social Psychology Quarterly 70(2):199-217.

Morris, Steven, Gary G Yen et al. 2005. "Construction of bipartite and unipartite weighted networks from collections of journal papers.” arXiv preprint physics/0503061 .

Mote, Jonathon E. 2005. "R\&D ecology: using 2-mode network analysis to explore complexity in R\&D environments." Journal of Engineering and Technology Management 22(1):93-111.

Newman, Mark EJ, Steven H Strogatz and Duncan J Watts. 2001. "Random graphs with arbitrary degree distributions and their applications." Physical Review E 64(2):026118-1-17.

Niekamp, Anne-Marie, Liesbeth AG Mercken, Christian JPA Hoebe and Nicole HTM DukersMuijrers. 2013. "A sexual affiliation network of swingers, heterosexuals practicing risk behaviours that potentiate the spread of sexually transmitted infections: A two-mode approach.” Social Networks 35(2):223-236. 
Opsahl, Tore. 2013. "Triadic closure in two-mode networks: Redefining the global and local clustering coefficients.” Social Networks 35(2):159-167.

Patison, KP, E Quintane, DL Swain, G Robins and P Pattison. 2015. "Time is of the essence: an application of a relational event model for animal social networks." Behavioral ecology and sociobiology 69(5):841-855.

Pilny, Andrew, Aaron Schecter, Marshall Scott Poole and Noshir Contractor. 2016. "An illustration of the relational event model to analyze group interaction processes." Group Dynamics: Theory, Research, and Practice 20(3):181.

Pilny, Andrew, Jeffrey D Proulx, Ly Dinh and Ann L Bryan. 2017. “An Adapted Structurational Framework for the Emergence of Communication Networks." Communication Studies 68(1):72-94.

Plickert, Gabriele, Rochelle R Cote and Barry Wellman. 2007. "It's not who you know, it's how you know them: Who exchanges what with whom?" Social networks 29(3):405-429.

Quintane, Eric and Gianluca Carnabuci. 2016. "How Do Brokers Broker? Tertius Gaudens, Tertius Iungens, and the Temporality of Structural Holes.” Organization Science 27(6):13431360.

Quintane, Eric, Guido Conaldi, Marco Tonellato and Alessandro Lomi. 2014. "Modeling Relational Events. A Case Study on an Open Source Software Project." Organizational Research Methods 17(1):23-50.

Quintane, Eric, Philippa E Pattison, Garry L Robins and Joeri M Mol. 2013. "Short-and longterm stability in organizational networks: Temporal structures of project teams." Social Networks 35(4):528-540.

R Core Team. 2016. R: A Language and Environment for Statistical Computing. Vienna, Austria: R Foundation for Statistical Computing. https://WwW.R-project.org/ (last access: January 11, 2017). 
Robins, Garry and Malcolm Alexander. 2004. "Small worlds among interlocking directors: Network structure and distance in bipartite graphs." Computational E Mathematical Organization Theory 10(1):69-94.

Schaefer, David R, John M Light, Richard A Fabes, Laura D Hanish and Carol Lynn Martin. 2010. "Fundamental principles of network formation among preschool children." Social Networks 32(1):61-71.

Stadtfeld, Christoph and Andreas Geyer-Schulz. 2011. "Analyzing event stream dynamics in two-mode networks: An exploratory analysis of private communication in a question and answer community." Social Networks 33(4):258-272.

Stephen, Andrew T and Olivier Toubia. 2009. "Explaining the power-law degree distribution in a social commerce network." Social Networks 31(4):262-270.

Surma, Jerzy. 2016. "Social exchange in online social networks. The reciprocity phenomenon on Facebook." Computer Communications 73:342-346.

Tam Cho, Wendy K and James H Fowler. 2010. "Legislative success in a small world: Social network analysis and the dynamics of congressional legislation." The Journal of Politics 72(01):124-135.

Tranmer, Mark, Christopher Steven Marcum, F Blake Morton, Darren P Croft and Selvino R de Kort. 2015. "Using the relational event model (REM) to investigate the temporal dynamics of animal social networks." Animal behaviour 101:99-105.

Trivers, Robert L. 1971. “The evolution of reciprocal altruism.” The Quarterly review of biology $46(1): 35-57$.

Vu, Duy, Philippa Pattison and Garry Robins. 2015. "Relational event models for social learning in MOOCs." Social Networks 43:121-135.

Vu, Duy Q., David Hunter, Padhraic Smyth and Arthur U. Asuncion. 2011. Continuous-Time Regression Models for Longitudinal Networks. In Advances in Neural Information Process- 
ing Systems 24, ed. J. Shawe-Taylor, R. S. Zemel, P. L. Bartlett, F. Pereira and K. Q. Weinberger. Curran Associates, Inc. pp. 2492-2500.

URL: http://papers.nips.cc/paper/4436-continuous-time-regression-models-for-longitudinalnetworks.pdf

Wasserman, Stanley and Katherine Faust. 1994. Social network analysis: Methods and applications. Vol. 8 Cambridge: Cambridge University Press.

Welbers, Kasper and Wouter de Nooy. 2014. "Stylistic accommodation on an internet forum as bonding: Do posters adapt to the style of their peers?" American Behavioral Scientist 58(10):1361-1375.

Wilson, Rick K and Cheryl D Young. 1997. “Cosponsorship in the US Congress.” Legislative Studies Quarterly 22:25-43.

Xia, Donggeng, Shawn Mankad and George Michailidis. 2016. "Measuring Influence of Users in Twitter Ecosystems Using a Counting Process Modeling Framework." Technometrics 58(3):360-370.

Zenk, Lukas and Christoph Stadtfeld. 2010. "Dynamic organizations. How to measure evolution and change in organizations by analyzing email communication networks." ProcediaSocial and Behavioral Sciences 4:14-25.

Zhu, Mengxiao, Yun Huang and Noshir S Contractor. 2013. "Motivations for self-assembling into project teams." Social Networks 35(2):251-264. 


\section{SI Online \\ Trading Favors - Examining the Temporal Dynamics of Reciprocity In Congressional Collaborations Using Relational Event Models}




\section{Additional Information on Control Variables}

\subsection{Previous Sponsorship Statistic}

Previous sponsorship captures four-cycles that are closed with the current event involving member $a$ and bill $b$. The four-cycle statistic (see Figure 1(a)) entails three past events: (a, j), (i, b) and $(i, j)$, all of which could be weighted according to the time difference between their occurrence in the sequence and the present event time $t$. However, since the four-cycle is composed of only active sponsoring events, events $(a, j)$ and $(i, j)$ occur at the same time. Therefore, the second term is reduced to a 0/1-dummy variable to reduce redundancy. The second term, (i, b), also cannot be weighted in time, as it gathers all members that currently actively cosponsor bill $b$ and therefore fall into the same time-spot as $t$.

The statistic can be operationalized as follows:

$$
\text { previousSponsorship }\left(G_{t} ; a, b\right)=\frac{\sum_{i \in A \backslash\{a\} ; j \in B \backslash\{b\}} w_{t}^{a c}(a, j) \cdot e_{t}^{a c}(i, b) \cdot e_{t}^{a c}(i, j)}{\sum_{i \in A \backslash\{a\}} e_{t}^{a c}(i, b)},
$$

where the network of past events $G_{t}$ is filtered for instances where $a$ and other cosponsors of bill $b$ actively cosponsored another bill $j$ together. A positive coefficient in the logistic regression on active cosponsorship indicates that members have a tendency to work with other members with whom they've worked together in the past. As such, the effect captures a form of inertia, where past collaboration partners are used in future collaborations. A positive coefficient in the Cox model on time-to-cosponsoring indicates that present member $a$ decides to cosponsor bill $b$ faster, if $a$ has worked on other bills with member $i$ in the past, and member $i$ sponsored the current bill as well.

\subsection{Cosponsoring Similarity Statistic}

Similarly to previous sponsorship or the reciprocity statistic presented in the paper, the cosponsoring similarity statistic captures a closing four-cycle with passive cosponsorship events:

$$
\text { CosponsoringSimilarity }\left(G_{t} ; a, b\right)=\frac{\sum_{i \in A \backslash\{\} ; j \in B \backslash\{b\}} w_{t}^{p c}(a, j) \cdot e_{t}^{a c}(i, b) \cdot e_{t}^{p c}(i, j) \cdot e^{\left(-\left(\left|t_{j}^{a c}-t_{i j}\right|\right) \cdot \frac{\ln (2)}{T_{1 / 2}}\right)}}{\sum_{i \in A \backslash\{a\}}^{a c} e_{t}^{a c}(i, b)}
$$

The statistic runs through the network of past events and checks how often member $a$ and one of the active sponsors of bill $b$ have cosponsored the same bills in the past. More weight is given to recent cosponsoring activity of $a$ as well as fast reaction time of member $i$ cosponsoring bill $j$ in the past.

A positive coefficient in the logistic regression on active cosponsorship indicates that members have a tendency to start collaboration with each other, if they have passively cosponsored the same bills in the past. As such, the variable measures something like ideological compatibility of two members embedded in the same cosponsoring network.

A positive coefficient in the Cox model on time-to-cosponsoring indicates that members tend to cosponsor a bill by member $i$ faster, if they have cosponsored the same bills in the past. 


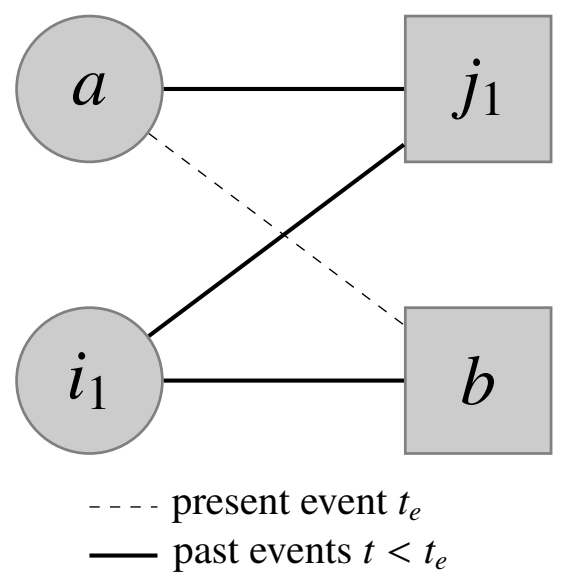

(a) closing four-cycle

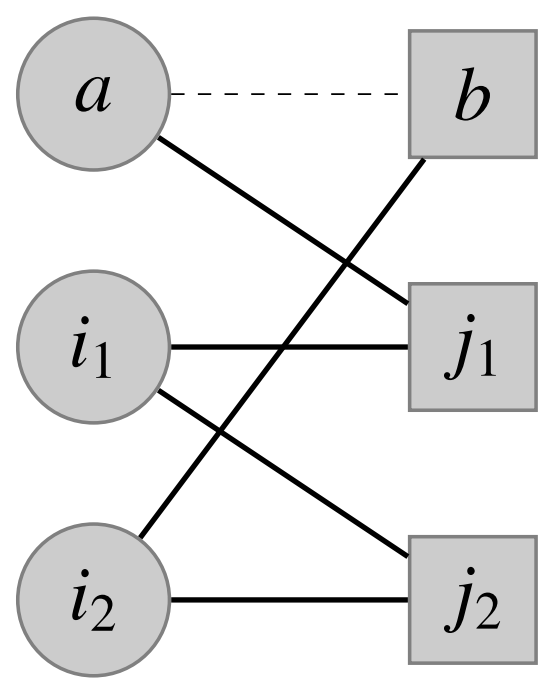

(b) closing six-cycle

Figure 1: Network effects featuring the closing four-cycle and closing six-cycle effect. Sender nodes are represented as circles, target nodes as squares.

This captures whether or not members use passive cosponsorship as signals and react to them in a temporal fashion.

\subsection{Shared Partner Statistic}

Popular network statistics in one-mode networks are triad or shared partner statistics. They measure the propensity of two nodes, which each tie to the same third node, to become tied as well. In two-mode networks the effect is mitigated via the second mode. It measures whether a sender node $a$ has a tendency to become involved with a target node $b$ given that other nodes $i$ have already linked to $b$, and $a$ and $i$ share a large number of other target nodes (see Figure 1(b)). The effect measures whether weak ties eventually become strong ties and sender nodes engage with loosely connected other senders due to their previous engagement with a shared partner.

For each sender node $a$ of the current target $b$, the term measures the number of sender nodes $i_{1}$ that two nodes $a$ and $i_{2}$ have in common:

$\operatorname{triadicClosure}\left(G_{t} ; a, b\right)=\frac{\sum_{\substack{i_{2} \in A \backslash\left\{i_{1}\right\} ; j_{1} \in B \backslash\left\{j_{2}\right\} \\ i_{1} \in A \backslash\left\{i_{2}\right\} ; j_{2} \in B \backslash\left\{j_{1}\right\}}} w_{t}^{a c}\left(a, j_{1}\right) \cdot e_{t}^{a c}\left(i_{2}, b\right) \cdot e_{t}^{a c}\left(i_{1}, j_{1}\right) \cdot e_{t}^{a c}\left(i_{1}, j_{2}\right) \cdot e_{t}^{a c}\left(i_{2}, j_{2}\right)}{\sum_{i_{2} \in A \backslash\{a\}} e_{t}^{a c}\left(i_{2}, b\right)}$

\subsection{Member Activity Statistic}

The member activity statistic captures outdegree statistics for the current member $a$ at event time $t$. 


$$
\text { activitySender }\left(G_{t} ; a, b\right)=\sum_{j \in B} w_{t}(a, j)
$$

The statistic runs through the network of past events $G_{t}$ and sums up all events that include actor $a$. The exponential weight function is used to give more recent events more weight. The half-life parameter controls the decay and was set to 20 event days for both passive and active cosponsorship models to capture recent member activity. A positive coefficient in the logistic regression on active cosponsorship indicates that members who have recently sponsored or cosponsored a bill are more likely to be part of a new collaboration team. A positive coefficient in the Cox model for time-to-cosponsorship indicates a positive increase in the hazard of event occurrence if a member has been active in the recent past. Figure 2(a) shows a graphical representation of the actor activity statistic.

\subsection{Bill Popularity Statistic}

Bill popularity measures target indegree for the current target $b$ at event time $t$.

$$
\text { popularityTarget }\left(G_{t} ; a, b\right)=\sum_{i \in A} w_{t}^{p c}(i, b)
$$

The statistic runs through the network of past events $G_{t}$ and sums up all events that include bill $b$. The statistic is used in the Cox model on time-to-cosponsoring to capture recent activity on the focal bill $b$. The term is specified with a half-life parameter of 3 event days, giving events that occurred three days ago only half the weight. As such, the statistic spikes only if within the past few days another member cosponsored the bill. The term is used to capture whether or not members react to other members cosponsoring the same bill. Furthermore, the effect can be coupled with a homophily term, to capture past events that stem from members that share a attribute with focal member $a$.

Ideological differences between these cosponsoring members $i$ and $a$ are calculated, as well as state and neighboring state homophily. Results are reported in Table 6 and show that ideological differences do not matter in signaling member $a$ to also cosponsor the bill, but state and neighboring state homophily do.

\subsection{Homophily Variables}

Several homophily variables are added to control for group formation due to shared similarities. Two statistics are used, one for categorical member attributes, and one for continuous member attributes.

The categorical homophily variable simply counts the number of active cosponsors of bill $b$ that share the same attribute $x$ as member $a$.

$$
\operatorname{homophily}\left(G_{t}, a, b\right)=\sum_{i \in A} e_{t}(i, b)\left[x_{a}=x_{i}\right]
$$




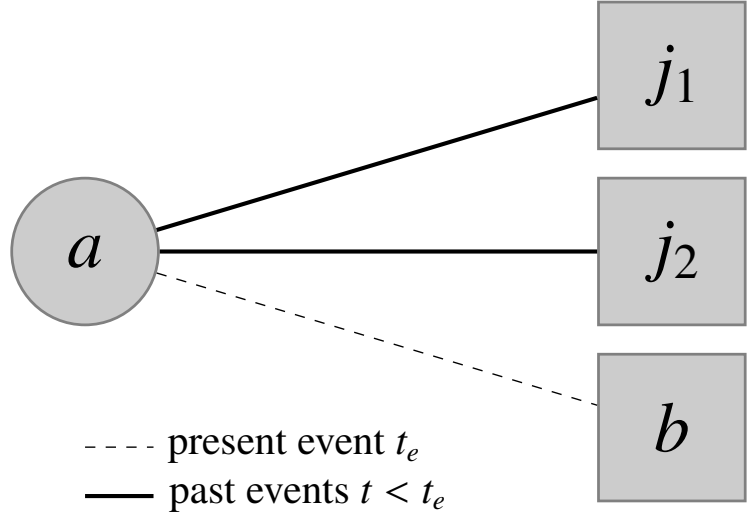

(a) Sender activity

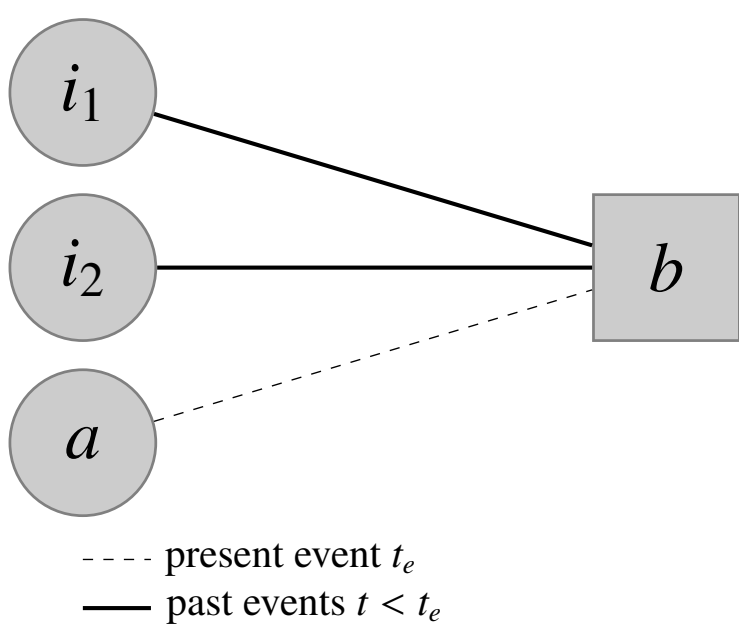

(b) Target popularity

Figure 2: Network effects featuring sender activity and target popularity. Sender nodes are represented as circles, target nodes as squares.

The continuous homophily variable measures for each active cosponsor of bill $b$ the differences between $i$ and $a$ in terms of $z$.

$$
\text { absoluteDifference }\left(G_{t}, a, b\right)=\sum_{i \in A} e_{t}(i, b) \cdot\left|z_{a}-z_{i}\right|
$$

Positive coefficients in the logistic regression on active cosponsorship indicates that members have a tendency to work with members with whom they share similar attributes. For the absolute difference, the interpretation of a positive coefficient is reversed: a positive coefficient indicates that as differences between two members increase, they are more likely to form a collaboration team.

Interpretations for variables in the Cox models on time-to-cosponsoring are analogous.

\subsection{Additional Control Variables}

As mentioned in the article, several member attributes were included as exogenous control variables in both models. Among them are their gender, their years of service as well as their deviance from the mean ideology scores. 


\section{Sensitivity Check using Two-Mode Exponential Random Graph Models}

\subsection{Exponential Random Graph Models}

Exponential random graph models (ERGMs) are used to determine how members of Congress actively or passively cosponsor a bill.

Two separate ERGMs are calculated for active and passive cosponsorship of energy policy related bills. $N_{e}^{a c}$ refers to the active cosponsorship networks on energy bills and $N_{e}^{p c}$ refers to the passive cosponsorship networks on energy bills. Just like in the REM, however, network statistics are calculated over the full networks, $N^{a c}$ for the active cosponsorship network and $N^{p c}$ for the passive cosponsorship network.

ERGMs are a powerful tool to explain the structure of network snapshots. In very short terms, ERGMs model the probability that a specific network structure is observed over all possible network permutations (see Cranmer and Desmarais 2011 for a detailed explanation of ERGMs and Cranmer et al. (2017) for the most recent primer on inferential network analysis).

Markov Chain Monte Carlo Maximum Likelihood Estimation (MCMC MLE) is used to estimate the models with the ergm package (Hunter et al., 2008) in R (R Core Team, 2016). Goodness of fit analysis is performed using the btergm package (Leifeld, Cranmer and Desmarais, 2017) by comparing network statistics to 500 simulated networks based on the estimation of the model. Tables are reported using the texreg package (Leifeld, 2013).

\subsection{Operationalization of Two-Mode ERGM Terms}

Operationalizations of network term are comparable to the REM terms. However, instead of accounting for time and only taking into account the network of past events to count configurations, the ERGM terms use raw frequencies of the networks for the entire time span.

\subsection{ERGM on Active Cosponsorship}

Table 1 shows the results of the ERGM on the two-mode active cosponsorship network. Results indicate a positive and significant reciprocity effect, indicating that members who cosponsored each others bills also have a tendency to work together. As ERGMs report correlations and disregard time, it is unclear whether past cosponsorship lead to future collaboration on new bills or whether past collaborations lead the members to cosponsor each other's bills afterwards. As such, the results of the ERGM can vary to those of the reported REM on active cosponsorship.

Furthermore, there is a strong tendency to repeatedly work with the same members (positive and significant result of the 'inertia' term). However, members cosponsor the same bills do not have a tendency to work together on new bills. The member activity term is measured using a geometrically weighted degree distribution term Hunter $(2007,224)$. A negative coefficient for the geometrically-weighted degree distribution term indicates that the network is more centralized due to its large variance in the degree distribution among the nodes (Levy, 2016). The control variable for triadic closure shows a negative coefficient, indicating that having more shared partners in common with other members who actively cosponsor a bill does not correlate with working together on other bills. It is possible that previous studies that reported strong triadic closure effects Cranmer and Desmarais (e.g., 2011); Craig et al. (e.g., 2015) may have 
Degree (first mode)

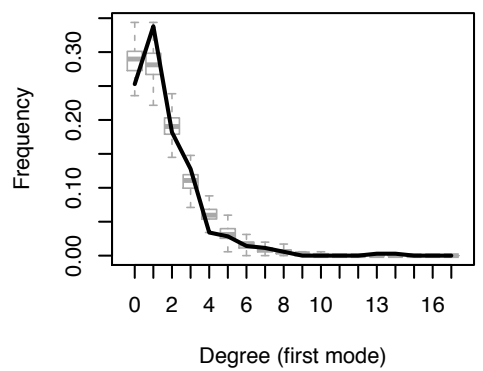

Dyad-wise shared partners

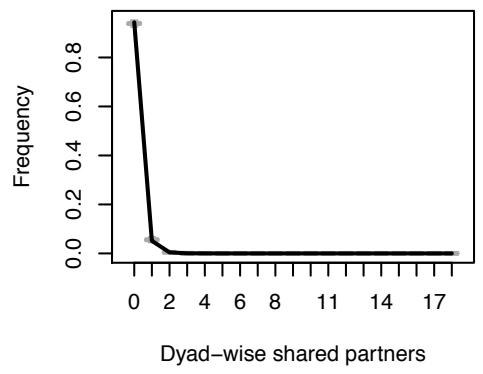

Degree (second mode)

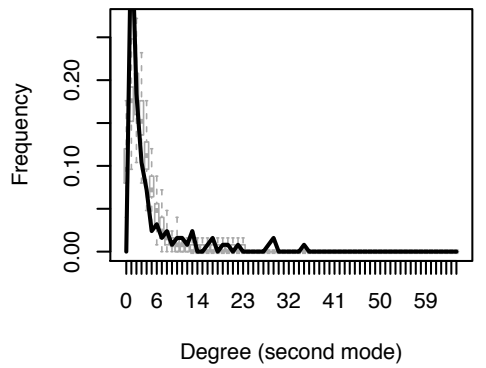

Geodesic distances

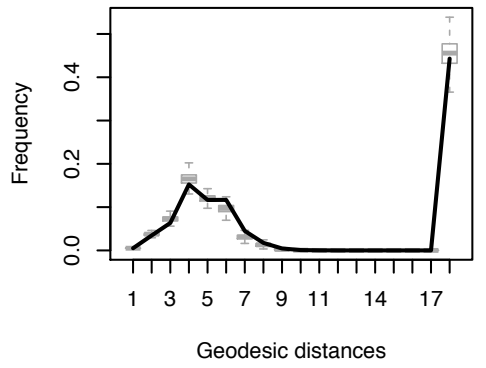

k-star (second mode)

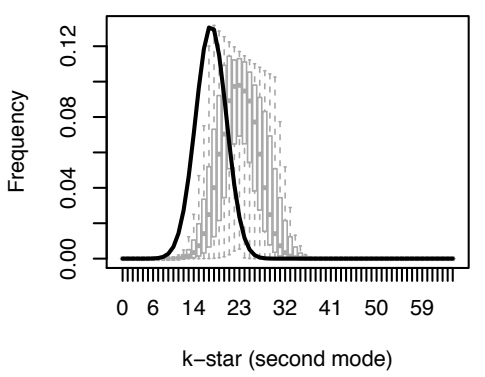

ROC and PR curve

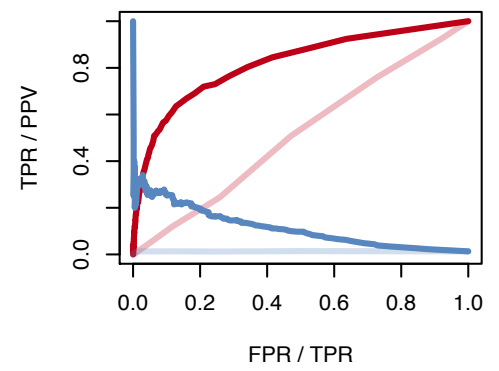

Figure 3: Goodness-of-fit statistics for the ERGM on active cosponsorship reported in Table 1. 500 networks are simulated from the ERGM.

overestimated triadic closure by projecting the two-mode networks into one-mode networks (Borgatti and Everett, 1997; Latapy, Magnien and Del Vecchio, 2008; Opsahl, 2013; Everett and Borgatti, 2013).

As for the homophily and other control variables, the results are comparable to those of the REM reported in the paper. Figure 3 reports goodness-of-fit statistics for the two-mode ERGM, calculated using the btergm-package (Leifeld, Cranmer and Desmarais, 2017). Overall the fit is acceptable.

\subsection{ERGM on Passive Cosponsorship}

Table 2 reports the results of the two-mode ERGM on the passive cosponsorship network. The ERGM on passive cosponsorship shows how endogenous and exogenous factors affect the passive cosponsorship network, disregarding the timing of these cosponsorship ties. As such, the results are not comparable to the REM, as the REM examines the duration it takes for a member to cosponsor a bill. However, the ERGM does check, whether reciprocity is a factor in passive cosponsorship, i.e., whether or not members actually reciprocate each other's support.

Results indicate that reciprocity is a strong factor in passive cosponsorship networks. Members have a strong tendency to reciprocate cosponsorship favors by cosponsoring bills that have been introduced by members from whom they received cosponsorship supports on their bill.

As for control variables, members who cosponsored the same bills tend to cosponsor each other's bills. However, members who worked together on multiple bills show negative effects 
Table 1: Results of the two-mode ERGM on active cosponsorship

\begin{tabular}{|c|c|}
\hline & $\begin{array}{c}(1) \\
\text { ERGM }\end{array}$ \\
\hline \multicolumn{2}{|l|}{ Reciprocity } \\
\hline Reciprocity: received cosponsor support & $\begin{array}{c}0.03^{* *} \\
(0.01)\end{array}$ \\
\hline \multicolumn{2}{|l|}{ Other network statistics } \\
\hline Inertia: sponsored together & $\begin{array}{l}0.03^{* * *} \\
(0.01)\end{array}$ \\
\hline Similarity: Cosponsored the same bills & $\begin{array}{r}-0.01^{*} \\
(0.00)\end{array}$ \\
\hline Member activity & $\begin{array}{c}-2.01^{* * *} \\
(0.24)\end{array}$ \\
\hline Shared partners & $\begin{array}{c}-0.01^{* * *} \\
(0.00)\end{array}$ \\
\hline \multicolumn{2}{|l|}{ Homophily/heterophily variables } \\
\hline Ideological differences & $\begin{array}{c}-2.18^{* * *} \\
(0.21)\end{array}$ \\
\hline Years of service differences & $\begin{array}{c}-0.04^{* * *} \\
(0.01)\end{array}$ \\
\hline State homophily & $\begin{array}{l}1.48^{* * *} \\
(0.17)\end{array}$ \\
\hline Neighboring state & $\begin{array}{l}0.84^{* * *} \\
(0.18)\end{array}$ \\
\hline Gender homophily & $\begin{array}{c}-0.98^{* * *} \\
(0.16)\end{array}$ \\
\hline Ethnicity homophily & $\begin{array}{r}-0.20 \\
(0.12)\end{array}$ \\
\hline \multicolumn{2}{|l|}{ Controls } \\
\hline Extreme ideology & $\begin{array}{r}-0.52^{*} \\
(0.21)\end{array}$ \\
\hline Gender $($ male $=1)$ & $\begin{array}{l}0.66^{* * *} \\
(0.11)\end{array}$ \\
\hline Years of Service & $\begin{array}{c}0.00 \\
(0.00)\end{array}$ \\
\hline General clustering & $\begin{array}{l}0.09^{* * *} \\
(0.01)\end{array}$ \\
\hline Intercept & $\begin{array}{c}-0.76^{*} \\
(0.38)\end{array}$ \\
\hline $\mathrm{BIC}$ & 4963.24 \\
\hline
\end{tabular}

${ }^{* * *} p<0.001,{ }^{* *} p<0.01,{ }^{*} p<0.05,{ }^{\prime} p<0.1 ;$ coefficients are reported as log-odds 
Degree (first mode)

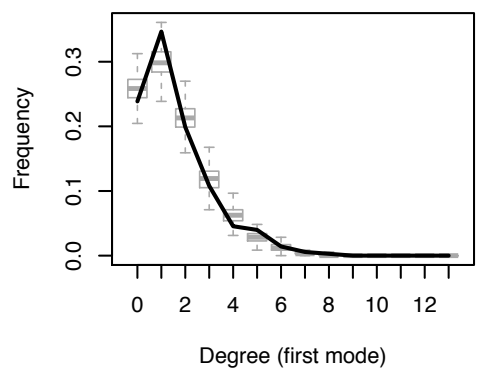

Dyad-wise shared partners

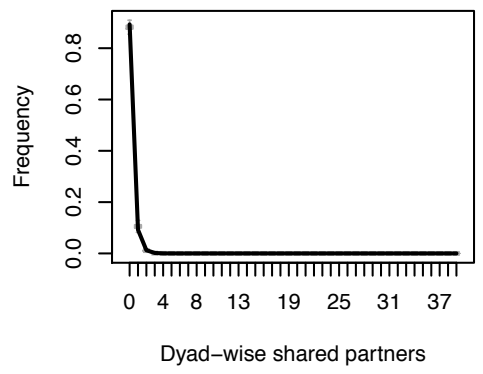

Degree (second mode)

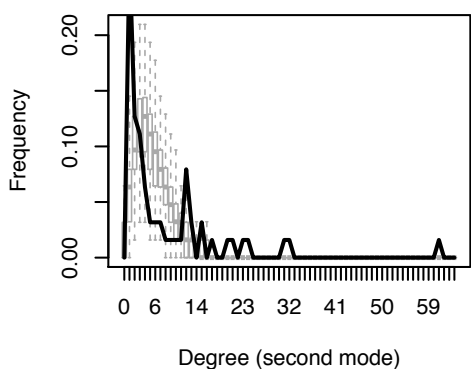

Geodesic distances

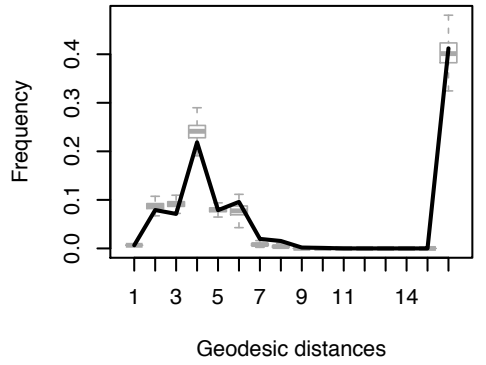

k-star (second mode)

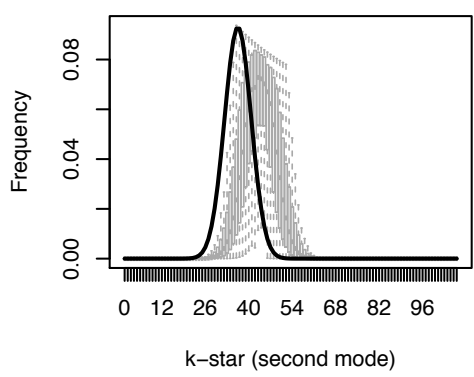

ROC and PR curve

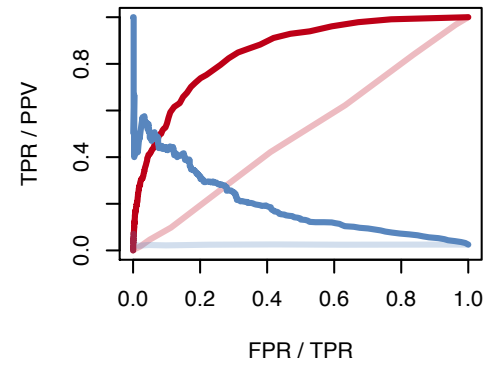

Figure 4: Goodness-of-fit statistics for the ERGM on active cosponsorship reported in Table 2. 500 networks are simulated from the ERGM

on passive cosponsorship. Furthermore, passive cosponsorship shows strong tendencies towards homophily on ideological similarities and geographic similarities (same state and neighboring state).

Figure 4 reports the results of the goodness-of-fit analyses for the ERGM. Overall, the fit is acceptable. 
Table 2: Results of the ERGM on the two-mode passive cosponsorship network

\begin{tabular}{|c|c|}
\hline & ERGM \\
\hline \multicolumn{2}{|l|}{ Reciprocity } \\
\hline Reciprocity: received cosponsor support & $\begin{array}{l}0.05^{* * *} \\
(0.01)\end{array}$ \\
\hline \multicolumn{2}{|l|}{ Other network statistics } \\
\hline Inertia: sponsored together & $\begin{array}{c}-0.03^{* * *} \\
(0.01)\end{array}$ \\
\hline Similarity: Cosponsored the same bills & $\begin{array}{c}0.01^{* * *} \\
(0.00)\end{array}$ \\
\hline Member activity & $\begin{array}{c}-1.64^{* * *} \\
(0.32)\end{array}$ \\
\hline General clustering (first mode) & $\begin{array}{l}0.06^{* * *} \\
(0.00)\end{array}$ \\
\hline \multicolumn{2}{|l|}{ Homophily/heterophily variables } \\
\hline Ideological differences & $\begin{array}{c}-2.73^{\text {*** }} \\
(0.22)\end{array}$ \\
\hline State homophily & $\begin{array}{l}1.81^{* * *} \\
(0.20)\end{array}$ \\
\hline Neighboring state & $\begin{array}{l}0.98^{* * *} \\
(0.19)\end{array}$ \\
\hline Gender homophily & $\begin{array}{c}-0.54^{* *} \\
(0.18)\end{array}$ \\
\hline Years of service differences & $\begin{array}{c}-0.03^{* *} \\
(0.01)\end{array}$ \\
\hline \multicolumn{2}{|l|}{ Controls } \\
\hline Extreme ideology & $\begin{array}{c}0.53^{*} \\
(0.23)\end{array}$ \\
\hline Gender $($ male $=1)$ & $\begin{array}{l}0.48^{* * *} \\
(0.12)\end{array}$ \\
\hline Years of Service & $\begin{array}{c}0.01^{* * *} \\
(0.00)\end{array}$ \\
\hline Edges & $\begin{array}{c}-4.16^{\text {*** }} \\
(0.46)\end{array}$ \\
\hline AIC & 4037.17 \\
\hline $\mathrm{BIC}$ & 4149.48 \\
\hline Log Likelihood & -2004.58 \\
\hline
\end{tabular}

${ }^{* * *} p<0.001,{ }^{* *} p<0.01,{ }^{*} p<0.05,{ }^{\prime} p<0.1$ 


\section{Active Cosponsorship: Additional Models and Results}

Table 3 reports the full results on the different REMs including interaction terms of party alignment on reciprocity in active cosponsorship event sequences.

The different operationalizations of reciprocity paint an interesting picture. The scaled reciprocity term shows a significant and positive effect for Republican members starting to work with other members from whom they have received cosponsorship support in the past. This positive effect is also present in time-weighted reciprocity statistics with short- to longerterm time weights. Giving more weight to recently traded favors does increase the likelihood of two members starting to work together. This finding holds for half-life parameters of 20 , 50 and 100 event days. However, the effect vanishes for the reciprocity term using a half-life parameter of 200 that take into account events taking place further in the past. This could point to the fact that when considering distant favor-trading, all members have some record of this, in other words, the control group (other members that did not work on the introduction of a specific bill) have traded at least a few favors with the active sponsors, diminishing the effect for the true-events (i.e., members that did work on the introduction of a specific bill).

Furthermore, Democratic members show negative effects of favor trading in the short-term (half-life parameters of 20 and 50). In the long-term (half-life of 100 and 200), the effect vanishes and control events and true events do not show any differences in favor trading.

The inclusion of the interaction effect does improve model fit a little bit and does not affect the results of the other control variables drastically. 
Table 3: Results of the logistic regression on active cosponsorship

\begin{tabular}{|c|c|c|c|c|c|}
\hline & REM scaled only & REM 20, 20 & REM 50, 20 & REM 10020 & REM 20020 \\
\hline \multicolumn{6}{|l|}{ Reciprocity } \\
\hline Reciprocity: received cosponsor support & $\begin{array}{c}-4.40^{\circ} \\
(2.37)\end{array}$ & $\begin{array}{c}-0.18^{* *} \\
(0.06)\end{array}$ & $\begin{array}{c}-0.23^{* *} \\
(0.08)\end{array}$ & $\begin{array}{c}-0.09 \\
(0.07)\end{array}$ & $\begin{array}{c}0.01 \\
(0.06)\end{array}$ \\
\hline Reciprocity X party (Republican = 1) & $\begin{array}{l}7.81^{\text {** }} \\
(2.51)\end{array}$ & $\begin{array}{l}0.26^{* * *} \\
(0.07)\end{array}$ & $\begin{array}{l}0.45^{* * *} \\
(0.10)\end{array}$ & $\begin{array}{c}0.27^{* *} \\
(0.08)\end{array}$ & $\begin{array}{c}0.09 \\
(0.07)\end{array}$ \\
\hline \multicolumn{6}{|l|}{ Other network statistics } \\
\hline Inertia: previously sponsored together & $\begin{array}{l}0.05^{* * *} \\
(0.01)\end{array}$ & $\begin{array}{l}0.05^{* * *} \\
(0.01)\end{array}$ & $\begin{array}{l}0.05^{\text {*** }} \\
(0.01)\end{array}$ & $\begin{array}{l}0.04^{\text {*** }} \\
(0.01)\end{array}$ & $\begin{array}{c}0.04^{* *} \\
(0.01)\end{array}$ \\
\hline Similarity: Cosponsored the same bills & $\begin{array}{c}0.01 \\
(0.01)\end{array}$ & $\begin{array}{c}0.00 \\
(0.01)\end{array}$ & $\begin{array}{c}-0.00 \\
(0.01)\end{array}$ & $\begin{array}{c}0.00 \\
(0.01)\end{array}$ & $\begin{array}{c}0.00 \\
(0.01)\end{array}$ \\
\hline Member activity & $\begin{array}{l}0.02^{* * *} \\
(0.01)\end{array}$ & $\begin{array}{l}0.02^{* * *} \\
(0.01)\end{array}$ & $\begin{array}{l}0.02^{* * * *} \\
(0.01)\end{array}$ & $\begin{array}{l}0.02^{\text {*** }} \\
(0.01)\end{array}$ & $\begin{array}{l}0.02^{* * *} \\
(0.01)\end{array}$ \\
\hline Shared partners & $\begin{array}{c}-0.00^{* * *} \\
(0.00)\end{array}$ & $\begin{array}{c}-0.00^{* * *} \\
(0.00)\end{array}$ & $\begin{array}{c}-0.01^{* * *} \\
(0.00)\end{array}$ & $\begin{array}{c}-0.00^{* * * *} \\
(0.00)\end{array}$ & $\begin{array}{c}-0.00^{* * *} \\
(0.00)\end{array}$ \\
\hline \multicolumn{6}{|l|}{ Homophily/heterophily variables } \\
\hline Ideological differences & $\begin{array}{c}-2.21^{* * *} \\
(0.21)\end{array}$ & $\begin{array}{c}-2.30^{* * *} \\
(0.20)\end{array}$ & $\begin{array}{c}-2.26^{* * *} \\
(0.20)\end{array}$ & $\begin{array}{c}-2.22^{* * *} \\
(0.20)\end{array}$ & $\begin{array}{c}-2.20^{* * *} \\
(0.20)\end{array}$ \\
\hline Years of service differences & $\begin{array}{c}-0.02^{* *} \\
(0.01)\end{array}$ & $\begin{array}{c}-0.02^{* *} \\
(0.01)\end{array}$ & $\begin{array}{c}-0.02^{* *} \\
(0.01)\end{array}$ & $\begin{array}{c}-0.02^{* *} \\
(0.01)\end{array}$ & $\begin{array}{c}-0.02^{* *} \\
(0.01)\end{array}$ \\
\hline State homophily & $\begin{array}{l}1.15^{\text {*** }} \\
(0.18)\end{array}$ & $\begin{array}{l}1.18^{* * * *} \\
(0.18)\end{array}$ & $\begin{array}{l}1.16^{\text {*** }} \\
(0.18)\end{array}$ & $\begin{array}{l}1.16^{\text {*** }} \\
(0.18)\end{array}$ & $\begin{array}{l}1.17^{* * * *} \\
(0.18)\end{array}$ \\
\hline Neighboring state & $\begin{array}{l}0.72^{* * *} \\
(0.16)\end{array}$ & $\begin{array}{l}0.74^{* * *} \\
(0.16)\end{array}$ & $\begin{array}{l}0.74^{* * *} \\
(0.16)\end{array}$ & $\begin{array}{l}0.72^{\text {*** }} \\
(0.16)\end{array}$ & $\begin{array}{l}0.71^{* * *} \\
(0.16)\end{array}$ \\
\hline Gender homophily & $\begin{array}{c}-1.65^{* * *} \\
(0.18)\end{array}$ & $\begin{array}{c}-1.61^{* * *} \\
(0.18)\end{array}$ & $\begin{array}{c}-1.66^{* * *} \\
(0.18)\end{array}$ & $\begin{array}{c}-1.62^{* * *} \\
(0.18)\end{array}$ & $\begin{array}{c}-1.56^{* * *} \\
(0.18)\end{array}$ \\
\hline Ethnicity homophily & $\begin{array}{c}-0.16 \\
(0.15)\end{array}$ & $\begin{array}{c}-0.16 \\
(0.15)\end{array}$ & $\begin{array}{c}-0.16 \\
(0.15)\end{array}$ & $\begin{array}{c}-0.17 \\
(0.15)\end{array}$ & $\begin{array}{c}-0.19 \\
(0.15)\end{array}$ \\
\hline \multicolumn{6}{|l|}{ Controls } \\
\hline Extreme ideology & $\begin{array}{c}0.04 \\
(0.34)\end{array}$ & $\begin{array}{c}0.10 \\
(0.33)\end{array}$ & $\begin{array}{c}0.08 \\
(0.33)\end{array}$ & $\begin{array}{c}0.03 \\
(0.33)\end{array}$ & $\begin{array}{c}-0.00 \\
(0.33)\end{array}$ \\
\hline Gender $($ male $=1)$ & $\begin{array}{l}1.50^{* * * *} \\
(0.20)\end{array}$ & $\begin{array}{l}1.45^{* * *} \\
(0.19)\end{array}$ & $\begin{array}{l}1.50^{* * * *} \\
(0.20)\end{array}$ & $\begin{array}{l}1.47^{\text {*** }} \\
(0.19)\end{array}$ & $\begin{array}{l}1.43^{* * *} \\
(0.19)\end{array}$ \\
\hline Years of Service & $\begin{array}{c}0.00 \\
(0.01)\end{array}$ & $\begin{array}{c}0.00 \\
(0.01)\end{array}$ & $\begin{array}{c}0.00 \\
(0.01)\end{array}$ & $\begin{array}{c}0.00 \\
(0.01)\end{array}$ & $\begin{array}{c}0.00 \\
(0.01)\end{array}$ \\
\hline Ordinal time & $\begin{array}{c}0.00 \\
(0.00)\end{array}$ & $\begin{array}{c}-0.00 \\
(0.00)\end{array}$ & $\begin{array}{c}0.00 \\
(0.00)\end{array}$ & $\begin{array}{c}0.00 \\
(0.00)\end{array}$ & $\begin{array}{c}-0.00 \\
(0.00)\end{array}$ \\
\hline Party $($ Republican $=1)$ & $\begin{array}{c}0.14 \\
(0.17)\end{array}$ & $\begin{array}{c}0.32^{*} \\
(0.14)\end{array}$ & $\begin{array}{c}0.14 \\
(0.15)\end{array}$ & $\begin{array}{c}0.19 \\
(0.16)\end{array}$ & $\begin{array}{c}0.36^{*} \\
(0.17)\end{array}$ \\
\hline Intercept & $\begin{array}{c}-3.76^{* * *} \\
(0.36)\end{array}$ & $\begin{array}{c}-3.75^{* * *} \\
(0.36)\end{array}$ & $\begin{array}{c}-3.69^{* * *} \\
(0.36)\end{array}$ & $\begin{array}{c}-3.71^{* * *} \\
(0.36)\end{array}$ & $\begin{array}{c}-3.76^{\text {*** }} \\
(0.36)\end{array}$ \\
\hline AIC & 4403.37 & 4402.07 & 4395.33 & 4403.58 & 4411.17 \\
\hline $\mathrm{BIC}$ & 4554.70 & 4553.40 & 4546.65 & 4554.90 & 4562.50 \\
\hline Log Likelihood & -2183.69 & -2183.04 & -2179.66 & -2183.79 & -2187.59 \\
\hline Deviance & 4367.37 & 4366.07 & 4359.33 & 4367.58 & 4375.17 \\
\hline Num. obs. & 33088 & 33088 & 33088 & 33088 & 33088 \\
\hline
\end{tabular}




\section{Endogeneity Concerns of Endogenous Network Statistics in Duration Models}

The problem of exogeneity of time-varying covariates in duration models has been addressed in a number of discussions. Box-Steffensmeier and Jones $(2004,95)$ write that '[o]ne of the strengths of event history models over the traditional regression model is the ability of the event history model to account for covariates that change values across the span of the observation period'. However, this inclusion of time-varying covariates also raises a problem. When interested in the hazard of event occurrence, covariates are used to explain factors that accelerate failure-time, i.e., time until a observation takes to move from one state (0) to another (1). Lancaster (1990) postulates that only covariates that are exogenous to the system under study can safely be included into the model. And he further argues, that a covariate is considered exogenous if the values are independent of the duration. However, Box-Steffensmeier and Jones (2004) argue that this definition is not sufficient to determine which variables are endogenous and which are exogenous. They argue that is 'largely a theoretical issue' (Box-Steffensmeier and Jones, 2004, 96). This is important, since the entire relational event model framework builds on the construction and analysis of endogenous network statistics that effect the survival of a dyad in a event sequence (Butts, 2008).

However, the time-weighted reciprocity statistic presented for passive cosponsorship, does seem to violate the exogeneity rule more than other endogenous statistics.

$$
\operatorname{closingFourCycle}\left(G_{t} ; a, b\right)=\sum_{\substack{i \in A \\ j \in B}} w_{t}(a, j) \cdot w_{t}(i, b) \cdot w_{t}(i, j)
$$

The problem stems from one weighted term $w_{t}(i, b)$ in Equation 8 and the way the duration is specified.

Instead of examining time-to-next-event, where the duration is specified as the time difference between the last and the focal event, time-to-cosponsoring examines the duration it takes member $a$ to issue a supportive signature on a specific bill $b$. This duration is equal to the time difference between the focal event $t$ and the time the dyad $(i, b)$ takes place. As such, the causing four-cylce statistic directly incorporates the time-to-cosponsoring duration measure into its calculation - which is something that does not happen for endogenous network statistics under the time-to-next-event specification for the duration.

The presented model for passive cosponsorship uses a Cox model with time-varying covariates. In a Cox model the actual duration time is not modeled, but rather the ordered failure times. The model calculates the hazard of event occurrence only at failure times by comparing the independent and control variables of true events (events where the failure occurred, i.e., where the passive cosponsoring event took place) to null events (events where failure did not occur, i.e., events where passive cosponsorship could have been issued, but was not).

Nevertheless, a simple example using a random variable multiplied with the weighted duration $w_{t}(i, b)$ does show that this inclusion of the time-to-cosponsoring duration renders the results of the variable highly significant. However, the random variable itself does not show any effect on the hazard of event occurrence (as it should due to its randomness).

For each event in the passive cosponsoring data set, a random variable between 1 and 100 was assigned: 
\#\# create a random variable

set.seed (1234)

dt.cut $\$$ nrIB_random <- $\operatorname{runif}($ nrow (dt.cut), 1, 100)

Afterwards, the random variable was weighted with $w_{t}(i, b)$ using different halflife parameters:

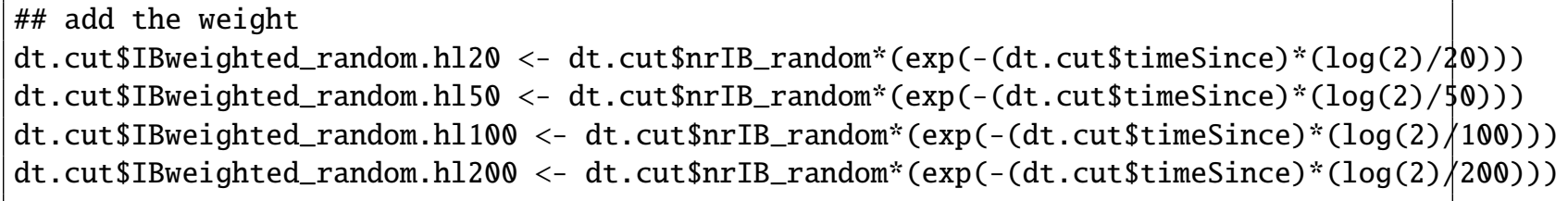

Afterwards, a Cox model was estimated to examine the effects of the random and weighted statistics on the hazard of event occurrence:

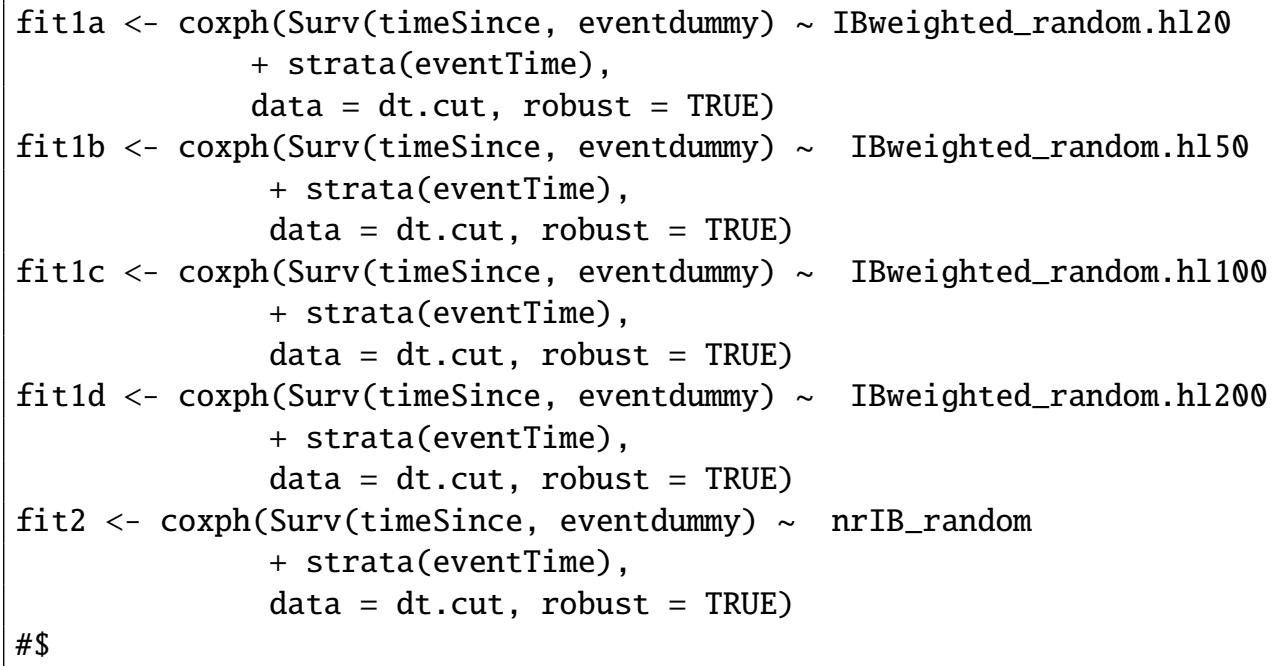

Table 4 reports the results of the Cox models. As expected, the random variable in Model 5 does not show any significant results on the hazard of event occurrence. However, the four time-weighted random variables do.

Figure 5 depicts the survival curves for model (1) and (4). The inclusion of the weight $w_{t}(i, b)$ does distort the survival curves somewhat. 
Table 4: Cox model using random variables weighted with the duration time-to-cosponsoring.

\begin{tabular}{lccccc}
\hline & $\begin{array}{c}\text { Model 1 } \\
\text { fit1a }\end{array}$ & $\begin{array}{c}\text { Model 2 } \\
\text { fit1b }\end{array}$ & $\begin{array}{c}\text { Model 3 } \\
\text { fit1c }\end{array}$ & $\begin{array}{c}\text { Model 4 } \\
\text { fit1d }\end{array}$ & $\begin{array}{c}\text { Model 5 } \\
\text { fit2 }\end{array}$ \\
\hline IBweighted_random.hl20 & $0.08^{* * *}$ & & & & \\
& $(0.01)$ & & & & \\
IBweighted_random.h150 & & $0.06^{* * *}$ & & & \\
& & $(0.00)$ & & & \\
IBweighted_random.hl100 & & & $0.04^{* * *}$ & & \\
& & & $(0.00)$ & & \\
IBweighted_random.hl200 & & & & $0.03^{* * *}$ & \\
& & & & $(0.00)$ & \\
nrIB_random & & & & & 0.00 \\
& & & & & $(0.00)$ \\
\hline AIC & 3261.71 & 3244.49 & 3329.50 & 3441.68 & 3565.56 \\
$\mathrm{R}^{2}$ & 0.02 & 0.02 & 0.02 & 0.01 & 0.00 \\
Max. R ${ }^{2}$ & 0.23 & 0.23 & 0.23 & 0.23 & 0.23 \\
Num. events & 447 & 447 & 447 & 447 & 447 \\
Num. obs. & 13587 & 13587 & 13587 & 13587 & 13587 \\
Missings & 0 & 0 & 0 & 0 & 0 \\
PH test & 0.26 & 0.24 & 0.48 & 0.91 & 0.69 \\
\hline
\end{tabular}

${ }^{* * *} p<0.001,{ }^{* *} p<0.01,{ }^{*} p<0.05$
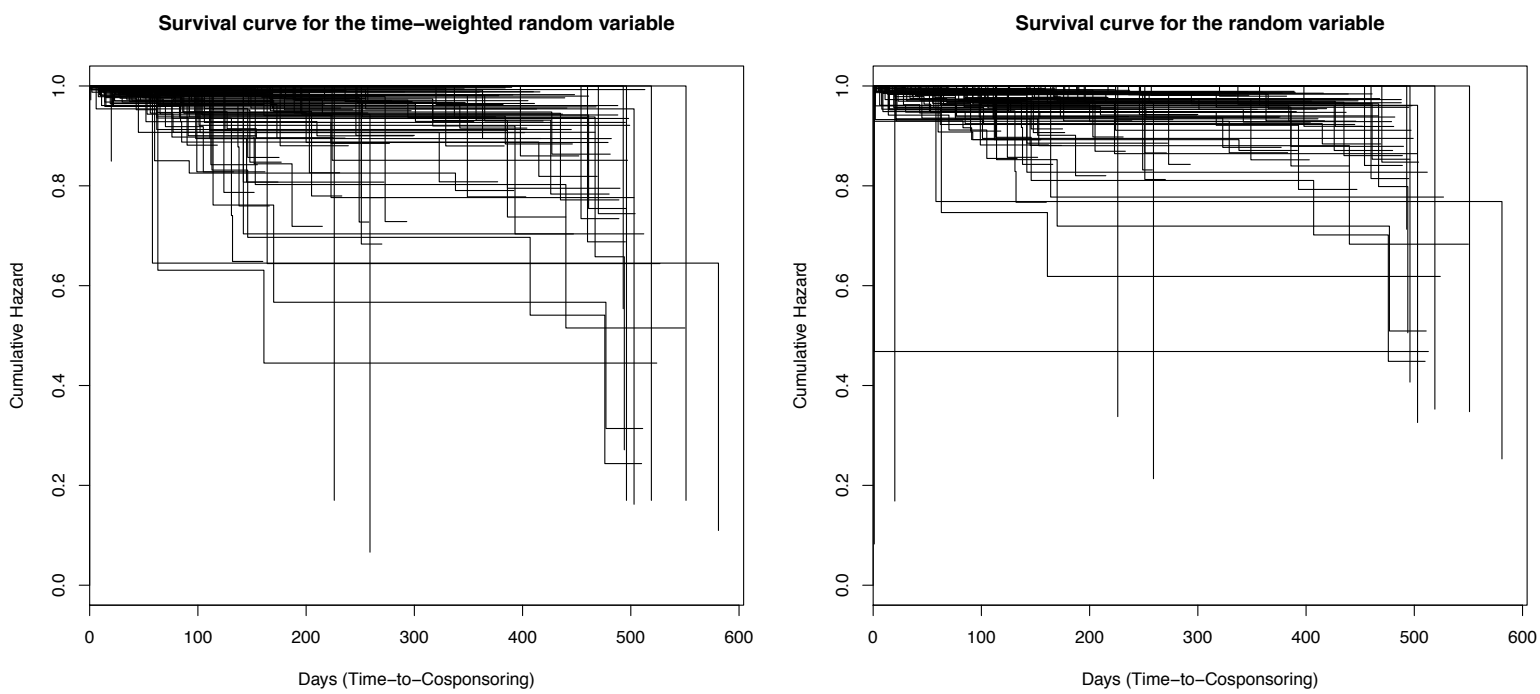

Figure 5: Survival curves for each strata in the passive cosponsorship model using a random variable as independent variable. Left panel shows survival curves for the random variable that has been multiplied with the weight $w_{t}(i, b)$, right panel shows the survival curves for the random variable 


\section{Passive Cosponsorship: Additional Models and Results}

Table 5 reports the results of the Cox model on time-to-cosponsoring including the interaction term for party alignment on reciprocity.

Results indicate that in the very short-term (half-life parameter of 20 event days), reciprocity does not have any effects on passive cosponsorship. However, by increasing the halflife parameter to give more weight to past events does show a negative effect on reciprocity for Democratic members of Congress. Republican members do not show any effects, regardless of how past events are weighted.

Table 6 examines bill popularity in closer detail. The idea is to examine whether members of Congress are affected by other members issuing their passive cosponsorship support for bill $b$. As such, bill popularity measures how many members have issued support for bill $b$ in the past. The term can be augmented with member attributes, to see which members' activities spurs another member $a$ into issuing support for bill $b$.

The results indicate that state and neighboring state homophily among passive cosponsors is the driving force. Interestingly, ideological differences do not affect the hazard of issuing support for bill $b$. This indicates that members form the same or neighboring state's signals are important. It is possible that a member is much more familiar with other members from their own state and from their neighboring states and therefore catches signals from these members much better than from members with whom they share ideological similarities. It would be interesting to see whether geographical distance confirms this signal perception hypothesis and how it interacts with ideological differences in future research. 
Table 5: Results of the Cox regression on time-to-passive-cosponsorship

\begin{tabular}{|c|c|c|c|c|c|}
\hline & REM scaled only & REM 20, 20 & REM 50, 20 & REM 100, 20 & REM 200, 20 \\
\hline \multicolumn{6}{|l|}{ Reciprocity } \\
\hline Reciprocity: received cosponsor support & $\begin{array}{r}-6.23^{*} \\
(2.89)\end{array}$ & $\begin{array}{c}-0.12 \\
(0.07)\end{array}$ & $\begin{array}{c}-0.32^{* *} \\
(0.11)\end{array}$ & $\begin{array}{c}-0.29^{* * *} \\
(0.09)\end{array}$ & $\begin{array}{c}-0.22^{* * *} \\
(0.06)\end{array}$ \\
\hline Reciprocity X party $($ Republican $=1)$ & $\begin{array}{c}4.47 \\
(2.96)\end{array}$ & $\begin{array}{c}0.11 \\
(0.09)\end{array}$ & $\begin{array}{c}0.25 \\
(0.14)\end{array}$ & $\begin{array}{c}0.18 \\
(0.12)\end{array}$ & $\begin{array}{c}0.11 \\
(0.09)\end{array}$ \\
\hline \multicolumn{6}{|l|}{ Other network statistics } \\
\hline Inertia: previously sponsored together & $\begin{array}{c}0.01 \\
(0.02)\end{array}$ & $\begin{array}{c}-0.01 \\
(0.02)\end{array}$ & $\begin{array}{c}0.01 \\
(0.02)\end{array}$ & $\begin{array}{c}0.01 \\
(0.02)\end{array}$ & $\begin{array}{c}0.01 \\
(0.02)\end{array}$ \\
\hline Similarity: Cosponsored the same bills & $\begin{array}{l}0.07^{* * *} \\
(0.02)\end{array}$ & $\begin{array}{l}0.07^{* * *} \\
(0.02)\end{array}$ & $\begin{array}{l}0.08^{* * *} \\
(0.02)\end{array}$ & $\begin{array}{l}0.08^{* * *} \\
(0.02)\end{array}$ & $\begin{array}{l}0.08^{* * *} \\
(0.02)\end{array}$ \\
\hline Member activity & $\begin{array}{c}0.05 \\
(0.03)\end{array}$ & $\begin{array}{c}0.04 \\
(0.03)\end{array}$ & $\begin{array}{c}0.05 \\
(0.03)\end{array}$ & $\begin{array}{c}0.05 \\
(0.03)\end{array}$ & $\begin{array}{c}0.05 \\
(0.03)\end{array}$ \\
\hline Short-term bill popularity & $\begin{array}{l}0.38^{* * *} \\
(0.05)\end{array}$ & $\begin{array}{l}0.37^{* * *} \\
(0.05)\end{array}$ & $\begin{array}{l}0.38^{* * *} \\
(0.05)\end{array}$ & $\begin{array}{l}0.38^{* * *} \\
(0.05)\end{array}$ & $\begin{array}{l}0.38^{* * *} \\
(0.05)\end{array}$ \\
\hline \multicolumn{6}{|l|}{ Homophily/heterophily variables } \\
\hline Ideological differences & $\begin{array}{c}-0.74^{*} \\
(0.33)\end{array}$ & $\begin{array}{r}-0.66^{*} \\
(0.32)\end{array}$ & $\begin{array}{c}-0.71^{*} \\
(0.32)\end{array}$ & $\begin{array}{r}-0.76^{*} \\
(0.32)\end{array}$ & $\begin{array}{r}-0.80^{*} \\
(0.33)\end{array}$ \\
\hline State homophily & $\begin{array}{l}1.40^{* * *} \\
(0.21)\end{array}$ & $\begin{array}{l}1.41^{* * *} \\
(0.21)\end{array}$ & $\begin{array}{l}1.45^{* * *} \\
(0.20)\end{array}$ & $\begin{array}{l}1.44^{* * *} \\
(0.20)\end{array}$ & $\begin{array}{l}1.40^{* * *} \\
(0.21)\end{array}$ \\
\hline Neighboring state & $\begin{array}{c}0.20 \\
(0.29)\end{array}$ & $\begin{array}{c}0.11 \\
(0.27)\end{array}$ & $\begin{array}{c}0.12 \\
(0.28)\end{array}$ & $\begin{array}{c}0.15 \\
(0.28)\end{array}$ & $\begin{array}{c}0.17 \\
(0.28)\end{array}$ \\
\hline Gender homophily & $\begin{array}{c}-1.77^{* *} \\
(0.60)\end{array}$ & $\begin{array}{c}-1.82^{* *} \\
(0.61)\end{array}$ & $\begin{array}{c}-1.74^{* *} \\
(0.59)\end{array}$ & $\begin{array}{c}-1.68^{* *} \\
(0.59)\end{array}$ & $\begin{array}{c}-1.68^{* *} \\
(0.58)\end{array}$ \\
\hline Years of service differences & $\begin{array}{c}0.01 \\
(0.01)\end{array}$ & $\begin{array}{c}0.01 \\
(0.01)\end{array}$ & $\begin{array}{c}0.01 \\
(0.01)\end{array}$ & $\begin{array}{c}0.01 \\
(0.01)\end{array}$ & $\begin{array}{c}0.01 \\
(0.01)\end{array}$ \\
\hline \multicolumn{6}{|l|}{ Additional controls } \\
\hline Extreme ideology & $\begin{array}{l}1.71^{* * *} \\
(0.33)\end{array}$ & $\begin{array}{l}1.57^{* * *} \\
(0.33)\end{array}$ & $\begin{array}{l}1.60^{* * *} \\
(0.33)\end{array}$ & $\begin{array}{l}1.65^{* * *} \\
(0.33)\end{array}$ & $\begin{array}{l}1.69^{* * *} \\
(0.33)\end{array}$ \\
\hline Gender $($ male $=1)$ & $\begin{array}{l}1.61^{* *} \\
(0.58)\end{array}$ & $\begin{array}{l}1.67^{* *} \\
(0.60)\end{array}$ & $\begin{array}{l}1.58^{* *} \\
(0.58)\end{array}$ & $\begin{array}{l}1.51^{* *} \\
(0.57)\end{array}$ & $\begin{array}{l}1.50^{* *} \\
(0.57)\end{array}$ \\
\hline Years of Service & $\begin{array}{c}0.01 \\
(0.01)\end{array}$ & $\begin{array}{c}0.00 \\
(0.01)\end{array}$ & $\begin{array}{c}0.00 \\
(0.01)\end{array}$ & $\begin{array}{c}0.00 \\
(0.01)\end{array}$ & $\begin{array}{c}0.00 \\
(0.01)\end{array}$ \\
\hline Party $($ Republican $=1)$ & $\begin{array}{c}0.17 \\
(0.21)\end{array}$ & $\begin{array}{c}0.20 \\
(0.17)\end{array}$ & $\begin{array}{c}0.11 \\
(0.19)\end{array}$ & $\begin{array}{c}0.12 \\
(0.21)\end{array}$ & $\begin{array}{c}0.16 \\
(0.22)\end{array}$ \\
\hline AIC & 3319.91 & 3322.81 & 3316.92 & 3314.73 & 3314.18 \\
\hline $\mathrm{R}^{2}$ & 0.02 & 0.02 & 0.02 & 0.02 & 0.02 \\
\hline Max. $\mathrm{R}^{2}$ & 0.23 & 0.23 & 0.23 & 0.23 & 0.23 \\
\hline Num. events & 447 & 447 & 447 & 447 & 447 \\
\hline Num. obs. & 13587 & 13587 & 13587 & 13587 & 13587 \\
\hline Missings & 0 & 0 & 0 & 0 & 0 \\
\hline PH test & 0.98 & 0.98 & 0.98 & 0.98 & 0.98 \\
\hline
\end{tabular}


Table 6: Results of the Cox regression on time-to-passive-cosponsorship examining bill popularity in closer detail

\begin{tabular}{|c|c|c|}
\hline & REM (1) & REM (2) \\
\hline \multicolumn{3}{|l|}{ Bill popularity } \\
\hline State homophily among recent cosponsors & $\begin{array}{l}0.42^{* *} \\
(0.16)\end{array}$ & $\begin{array}{c}0.38^{*} \\
(0.16)\end{array}$ \\
\hline Neighboring state homophily among recent cosponsors & $\begin{array}{l}0.40^{* *} \\
(0.14)\end{array}$ & $\begin{array}{l}0.38^{* *} \\
(0.15)\end{array}$ \\
\hline Ideological differences among recent cosponsors & $\begin{array}{c}0.04 \\
(0.04)\end{array}$ & $\begin{array}{c}0.03 \\
(0.04)\end{array}$ \\
\hline \multicolumn{3}{|l|}{ Other network statistics } \\
\hline Reciprocity: received cosponsor support & $\begin{array}{c}-0.14 \\
(0.08)\end{array}$ & $\begin{array}{c}-0.32^{* *} \\
(0.11)\end{array}$ \\
\hline Reciprocity X party (Republican $=1)$ & & $\begin{array}{c}0.29^{*} \\
(0.14)\end{array}$ \\
\hline Inertia: previously sponsored together & $\begin{array}{c}-0.01 \\
(0.02)\end{array}$ & $\begin{array}{c}0.00 \\
(0.02)\end{array}$ \\
\hline Similarity: Cosponsored the same bills & $\begin{array}{l}0.06^{* * *} \\
(0.02)\end{array}$ & $\begin{array}{l}0.07^{* * * *} \\
(0.02)\end{array}$ \\
\hline Member activity & $\begin{array}{c}0.03 \\
(0.03)\end{array}$ & $\begin{array}{c}0.05 \\
(0.03)\end{array}$ \\
\hline \multicolumn{3}{|l|}{ Homophily/heterophily variables } \\
\hline Ideological differences & $\begin{array}{c}-1.09^{* * *} \\
(0.31)\end{array}$ & $\begin{array}{r}-0.84^{*} \\
(0.34)\end{array}$ \\
\hline State homophily & $\begin{array}{l}1.25^{* * *} \\
(0.21)\end{array}$ & $\begin{array}{l}1.30^{* * *} \\
(0.20)\end{array}$ \\
\hline Neighboring state & $\begin{array}{c}0.11 \\
(0.25)\end{array}$ & $\begin{array}{c}-0.00 \\
(0.27)\end{array}$ \\
\hline Gender homophily & $\begin{array}{c}-1.62^{* *} \\
(0.57)\end{array}$ & $\begin{array}{l}-1.78^{* *} \\
(0.57)\end{array}$ \\
\hline Years of service differences & $\begin{array}{c}0.01 \\
(0.01)\end{array}$ & $\begin{array}{c}0.01 \\
(0.01)\end{array}$ \\
\hline \multicolumn{3}{|l|}{ Controls } \\
\hline Extreme ideology & $\begin{array}{l}1.72^{* * *} \\
(0.33)\end{array}$ & $\begin{array}{l}1.77^{* * *} \\
(0.33)\end{array}$ \\
\hline Gender $($ male $=1)$ & $\begin{array}{l}1.60^{* *} \\
(0.57)\end{array}$ & $\begin{array}{l}1.59^{* *} \\
(0.56)\end{array}$ \\
\hline Years of Service & $\begin{array}{c}0.00 \\
(0.01)\end{array}$ & $\begin{array}{c}0.00 \\
(0.01)\end{array}$ \\
\hline Party $($ Republican $=1)$ & & $\begin{array}{c}0.20 \\
(0.19)\end{array}$ \\
\hline AIC & 3428.77 & 3420.80 \\
\hline $\mathrm{R}^{2}$ & 0.01 & 0.01 \\
\hline Max. $\mathrm{R}^{2}$ & 0.23 & 0.23 \\
\hline Num. events & 447 & 447 \\
\hline Num. obs. & 13587 & 13587 \\
\hline Missings & 0 & 0 \\
\hline PH test & 0.93 & 0.96 \\
\hline
\end{tabular}




\section{References}

Borgatti, Stephen P and Martin G Everett. 1997. "Network analysis of 2-mode data." Social networks 19(3):243-269.

Box-Steffensmeier, Janet M and Bradford S Jones. 2004. Event history modeling: A guide for social scientists. Cambridge: Cambridge University Press.

Butts, Carter T. 2008. "A relational event framework for social action.” Sociological Methodology 38(1):155-200.

Craig, Alison, Skyler J Cranmer, Bruce A Desmarais, Christopher J Clark and Vincent G Moscardelli. 2015. "The Role of Race, Ethnicity, and Gender in the Congressional Cosponsorship Network." arXiv preprint arXiv:1512.06141 .

Cranmer, Skyler J and Bruce A Desmarais. 2011. "Inferential network analysis with exponential random graph models." Political Analysis 19(1):66-86.

Cranmer, Skyler J, Philip Leifeld, Scott D McClurg and Meredith Rolfe. 2017. "Navigating the range of statistical tools for inferential network analysis." American Journal of Political Science 61(1):237-251.

Everett, Martin G and Stephen P Borgatti. 2013. "The dual-projection approach for two-mode networks." Social Networks 35(2):204-210.

Hunter, David R. 2007. "Curved exponential family models for social networks." Social networks 29(2):216-230.

Hunter, David R, Mark S Handcock, Carter T Butts, Steven M Goodreau and Martina Morris. 2008. "ergm: A package to fit, simulate and diagnose exponential-family models for networks.” Journal of Statistical Software 24(3):nihpa54860.

Lancaster, Tony. 1990. The econometric analysis of transition data. Cambridge: Cambridge University Press.

Latapy, Matthieu, Clémence Magnien and Nathalie Del Vecchio. 2008. "Basic notions for the analysis of large two-mode networks." Social networks 30(1):31-48.

Leifeld, Philip. 2013. "texreg: Conversion of Statistical Model Output in R to LATEX and HTML Tables.” Journal of Statistical Software 55(8):1-24.

Leifeld, Philip, Skyler J Cranmer and Bruce A Desmarais. 2017. “Temporal Exponential Random Graph Models with btergm: Estimation and Bootstrap Confidence Intervals.” Journal of Statistical Software Forthcoming.

Levy, Michael A. 2016. "gwdegree: Improving interpretation of geometrically-weighted degree estimates in exponential random graph models." The Journal of Open Source Software 1(3).

Opsahl, Tore. 2013. "Triadic closure in two-mode networks: Redefining the global and local clustering coefficients." Social Networks 35(2):159-167. 
R Core Team. 2016. R: A Language and Environment for Statistical Computing. Vienna, Austria: R Foundation for Statistical Computing. https://www.R-project.org/ (last access: January 11, 2017). 